\title{
On the effect of dust particles on global cloud condensation nuclei and cloud droplet number
}

\author{
V. A. Karydis, ${ }^{1}$ P. Kumar, ${ }^{2,3}$ D. Barahona, ${ }^{4,5}$ I. N. Sokolik, ${ }^{1}$ and A. Nenes ${ }^{1,6}$ \\ Received 20 May 2011; revised 24 September 2011; accepted 26 September 2011; published 7 December 2011.
}

[1] Aerosol-cloud interaction studies to date consider aerosol with a substantial fraction of soluble material as the sole source of cloud condensation nuclei (CCN). Emerging evidence suggests that mineral dust can act as good $\mathrm{CCN}$ through water adsorption onto the surface of particles. This study provides a first assessment of the contribution of insoluble dust to global CCN and cloud droplet number concentration (CDNC). Simulations are carried out with the NASA Global Modeling Initiative chemical transport model with an online aerosol simulation, considering emissions from fossil fuel, biomass burning, marine, and dust sources. CDNC is calculated online and explicitly considers the competition of soluble and insoluble $\mathrm{CCN}$ for water vapor. The predicted annual average contribution of insoluble mineral dust to CCN and CDNC in cloud-forming areas is up to 40 and $23.8 \%$, respectively. Sensitivity tests suggest that uncertainties in dust size distribution and water adsorption parameters modulate the contribution of mineral dust to CDNC by 23 and $56 \%$, respectively. Coating of dust by hygroscopic salts during the atmospheric aging causes a twofold enhancement of the dust contribution to CCN; the aged dust, however, can substantially deplete in-cloud supersaturation during the initial stages of cloud formation and can eventually reduce CDNC. Considering the hydrophilicity from adsorption and hygroscopicity from solute is required to comprehensively capture the dust-warm cloud interactions. The framework presented here addresses this need and can be easily integrated in atmospheric models.

Citation: Karydis, V. A., P. Kumar, D. Barahona, I. N. Sokolik, and A. Nenes (2011), On the effect of dust particles on global cloud condensation nuclei and cloud droplet number, J. Geophys. Res., 116, D23204, doi:10.1029/2011JD016283.

\section{Introduction}

[2] Mineral dust is a major component of particulate matter in the atmosphere, accounting for more than $50 \%$ of the global aerosol load [Grini et al., 2005; Zender and Kwon, 2005]. Mineral aerosol may be composed of iron oxides (e.g., hematite, goethite), carbonates (e.g., calcite, dolomite), quartz, and clays (e.g., kaolinite, illite, and montmorillonite) [Chou et al., 2008; Coz et al., 2009; Lafon et al., 2006; Twohy et al., 2009]. Differences in parent soils, and emission and transport processes cause substantial changes in size distribution, composition, and morphology of dust particles [Jeong and Sokolik, 2007; Sokolik et al., 2001]. The long-range transport of dust particles can influence the

\footnotetext{
${ }^{1}$ School of Earth and Atmospheric Sciences, Georgia Institute of Technology, Atlanta, Georgia, USA.

${ }^{2}$ School of Chemical and Biomolecular Engineering, Georgia Institute of Technology, Atlanta, Georgia, USA.

${ }^{3}$ Now at SABIC Innovative Plastics, Selkirk, New York, USA.

${ }^{4}$ NASA Goddard Space Flight Center, Greenbelt, Maryland, USA.

${ }^{5}$ Also at I.M. Systems, Inc., Rockville, Maryland, USA.

${ }^{6}$ Also at School of Chemical and Biomolecular Engineering, Georgia Institute of Technology, Atlanta, Georgia, USA.
}

Copyright 2011 by the American Geophysical Union. 0148-0227/11/2011JD016283 composition and dynamic state of the atmosphere thousands of kilometers downwind of their source region [e.g., Kallos et al., 2007; Prospero et al., 2001]. Under favorable conditions, dust particles originating from Northern and Central Africa may be elevated and travel across the Atlantic Ocean toward the Caribbean [Chiapello et al., 2005; Kallos et al., 2006; Karyampudi and Carlson, 1988; Karyampudi et al., 1999] or across the Mediterranean toward Europe, affecting both air quality and meteorology in Southern Europe [Mitsakou et al., 2008; Querol et al., 2009]. Dust from the Gobi and Taklamakan deserts often crosses the Pacific and reaches the west coast of the Americas [Meskhidze et al., 2005a; Meskhidze et al., 2003; Sassen et al., 2002].

[3] Absorption of solar radiation by dust can modify the atmospheric thermodynamic structure, leading to suppression (or enhancement) of precipitation depending on cloud types and atmospheric conditions [Yin and Chen, 2007]. Moreover, dust particles are efficient ice nuclei (IN) and contribute to the formation of ice particles in cirrus and mixed-phase clouds [DeMott et al., 2003; Field et al., 2006; Teller and Levin, 2006; Barahona et al., 2010a]. Dust may also interact with sea salt, anthropogenic pollutants, and secondary organic aerosol, forming particles that consist of a "core" of insoluble mineral dust with coatings of soluble material [Gibson et al., 2007; Levin et al., 2005; Seisel et al., 2005]. 
Dust particles with a soluble coating are typically very efficient cloud condensation nuclei $(\mathrm{CCN})$, often maintaining their activity as IN [Levin et al., 2005]. According to Kelly et al. [2007], small amounts of highly soluble components greatly enhance the ability of fine dust particles to serve as CCN. Hoose et al. [2008a] have shown that, depending on the dust mineralogical composition, coating with soluble material from anthropogenic sources can lead to quasideactivation of natural dust ice nuclei. Moreover, due to their large size, dust particles can act as giant $\mathrm{CCN}$ that can form efficient collector drops and initiate the onset of drizzle and precipitation [Feingold et al., 1999; Levin and Cotton, 2009]. The same particles can strongly compete for water vapor in the nucleation zone of cloudy updrafts, potentially reducing supersaturation and cloud droplet formation [Barahona et al., 2010b]. According to Lee et al. [2009], $\mathrm{CCN}$ concentration decreases in dusty regions up to $10-20 \%$ because dust competes for condensable $\mathrm{H}_{2} \mathrm{SO}_{4}$, reducing the condensational growth of ultrafine mode particles to $\mathrm{CCN}$ sizes. On the other hand, below $0.1 \%$ supersaturation, $\mathrm{CCN}$ concentrations increase significantly in dusty regions due to the presence of coarse dust particles. Manktelow et al. [2010] found that $\mathrm{CCN}$-sized particles were depleted by an average of less than 5\% during an extreme dust event over E. China, Korea, and Japan, because decreases in fine aerosols were mostly compensated for by increases in coarse particles.

[4] Köhler theory (KT), which is currently used to describe droplet formation in atmospheric models, assumes that the CCN activity of aerosols depends solely on their curvature and the fraction of soluble material. There is emerging evidence though that insoluble species (like freshly emitted mineral dust) can also act as good CCN even if they lack appreciable amounts of soluble material. Koehler et al. [2009] and Herich et al. [2009] measured CCN activation of two types of regional dust samples (Northern Africa and Arizona Test Dust) and several clays (kaolinite, illite, and montmorillonite) at atmospherically relevant supersaturations. The high CCN activity was attributed to soluble ions present in the material. Further analysis of these data by Kumar et al. [2009a] showed the importance of including water adsorption effects in describing the hygroscopic and $\mathrm{CCN}$ behavior of mineral aerosol. This was later confirmed by Kumar et al. [2011a, 2011b] who studied the CCN activity of dry- and wet-generated clays and mineral dusts representative of major regional dust sources (Northern Africa, East Asia/China, and Northern America). The observed hygroscopicity could not be attributed to the soluble ions present, but rather to the strong water vapor adsorption on the particle surface. Lathem et al. [2011] also demonstrated the importance of adsorption for describing the water uptake properties of volcanic ash. Finally, Kumar et al. [2011b] presented a "unified dust activation framework" to treat the activation of dust internally mixed with soluble salts by considering the effects of adsorption and absorption on water activity.

[5] The dependence of CCN activity on dry diameter differs between particles for which soluble material dominates their composition and those which lack any appreciable amounts of solute. This difference needs to be accounted for in calculation of $\mathrm{CDNC}$ when the $\mathrm{CCN}$ population contains both particle types. Kumar et al. [2009b] developed a cloud droplet formation parameterization to address this need, which accounts for the effect of adsorption activation by assuming the $\mathrm{CCN}$ constitute an external mixture of soluble aerosol (that follow KT) and completely insoluble aerosol (that follow FHH adsorption activation theory, FHH-AT). Kumar et al. [2011a] also developed a framework to treat dust particles with substantial amounts of soluble material where the $\mathrm{CCN}$ activity is influenced by both adsorption and solute.

[6] To date, global models and studies that include the dust impacts on cloud droplet number assume that dust acts as $\mathrm{CCN}$ only when soluble material exists in the particles (and controls its hygroscopicity) [e.g., Hoose et al., 2008b; Kelly et al., 2007; Lee et al., 2009; Manktelow et al., 2010; Pringle et al., 2010a, 2010b; Solomos et al., 2011]. Here we assess for the first time the impact of water adsorption on the $\mathrm{CCN}$ activity of insoluble (dust) aerosol and the resulting contribution to global $\mathrm{CCN}$ and cloud droplet number. Simulations are carried out with the NASA Global Modeling Initiative (GMI) Chemical Transport Model using offline wind fields and an online aerosol simulation coupled with the Kumar et al. [2009b] activation parameterization. The sensitivity of the proposed modeling framework to the size distribution and the adsorption parameters controlling the dust CCN activity is investigated. Finally, the sensitivity of our simulations to the deposition of solute on dust particles is addressed by extending the Kumar et al. [2009b] parameterization that enables us to include the "unified" adsorptionabsorption activation theory of Kumar et al. [2011b] for describing the $\mathrm{CCN}$ activity of aged dust particles.

\section{Model Description}

\subsection{NASA Global Modeling Initiative (GMI)}

[7] The NASA GMI (https://gmi.gsfc.nasa.gov/gmi.html) is a modular 3-D chemistry and transport model (CTM), with the ability to carry out multiyear simulations for impact assessment studies. The detailed description of the framework is given by Rotman et al. [2001] and Considine et al. [2005]. The GMI aerosol model used in this study was contributed by Liu et al. [2005] and coupled to the GMICTM advection core. The aerosol module includes primary emissions, chemical production of sulfate in clear air and the in-cloud aqueous phase, gravitational sedimentation, dry deposition, wet scavenging in and below clouds, and hygroscopic growth. The model time step for chemistry is one hour. Model inputs include emissions of $\mathrm{SO}_{2}$ (fossil fuel and natural), DMS, $\mathrm{H}_{2} \mathrm{O}_{2}$, black carbon (from biomass burning and fossil fuel), organic carbon (fossil fuel, biomass burning, and natural), mineral dust (four size bins), and sea salt (four size bins), which are provided by Liu et al. [2005]. The $2 \%$ (by mole) of fossil-fuel sulfur emission is assumed to occur as primary sulfate aerosol to account for the rapid conversion of $\mathrm{SO}_{2}$ to $\mathrm{SO}_{4}^{2-}$ in combustion plumes. $\mathrm{SO}_{2}$ emissions also include sources from sporadic and continuously emitting volcanoes (averaged over a 25-year time period). Biofuel emissions are categorized as fossil fuels.

[8] Dust aerosol fluxes at every $6 \mathrm{~h}$ were generated with the approach of Ginoux et al. [2001], using the NASA Goddard Data Assimilation Office (DAO) meteorological fields for year 1997. To account for a systematic overestimation in calculated AOD over deserts, Liu et al. [2005] reduced the submicron dust $(0.1-1.25 \mu \mathrm{m}$ bin) emission flux by roughly twofold. With this modified emissions 
Table 1. Size Distribution Parameters Applied to Fossil Fuel, Biomass Burning, Marine, and Mineral Dust Aerosols

\begin{tabular}{|c|c|c|c|c|c|c|}
\hline Aerosol Type & $\begin{array}{c}\text { Aerosol } \\
\text { Components }\end{array}$ & $\begin{array}{l}\text { Density } \\
\left(\mathrm{g} \mathrm{cm}^{-3}\right)\end{array}$ & $\begin{array}{l}\text { Median } \\
\text { Diameter } \\
(\mu \mathrm{m})\end{array}$ & $\begin{array}{l}\text { Geometric } \\
\text { Standard } \\
\text { Deviation }\end{array}$ & $\begin{array}{l}\text { Number } \\
\text { Fraction }\end{array}$ & Reference \\
\hline Fossil fuel & $\begin{array}{c}\text { sulfate } \\
\text { organic carbon } \\
\text { black carbon }\end{array}$ & $\begin{array}{l}1.77 \\
1.2 \\
1.5\end{array}$ & 0.1 & 1.9 & 1 & Chuang et al. [1997]; Radke et al. [1988] \\
\hline Biomass burning & $\begin{array}{l}\text { organic carbon } \\
\text { black carbon }\end{array}$ & $\begin{array}{l}1.2 \\
1.5\end{array}$ & 0.16 & 1.65 & 1 & Anderson et al. [1996] \\
\hline Marine & $\begin{array}{c}\text { natural sulfate } \\
\text { sea salt }\end{array}$ & $\begin{array}{l}1.77 \\
2.2\end{array}$ & $\begin{array}{l}0.018 \\
0.075 \\
0.62\end{array}$ & $\begin{array}{l}1.4 \\
1.6 \\
2.7\end{array}$ & $\begin{array}{l}0.81 \\
0.18 \\
0.01\end{array}$ & Lance et al. [2004] \\
\hline Mineral dust (base case) & mineral dust & 2.6 & $\begin{array}{l}0.16 \\
1.4 \\
10\end{array}$ & $\begin{array}{l}2.1 \\
1.9 \\
1.6\end{array}$ & $\begin{array}{c}0.93 \\
0.07 \\
3 \times 10^{-6}\end{array}$ & d'Almeida et al. [1987] \\
\hline Mineral dust (sensitivity case) & mineral dust & 2.6 & $\begin{array}{l}0.18 \\
0.7 \\
1.5\end{array}$ & $\begin{array}{l}1.8 \\
1.4 \\
2.0\end{array}$ & $\begin{array}{l}0.76 \\
0.13 \\
0.11\end{array}$ & Chou et al. [2008] \\
\hline
\end{tabular}

scheme, Liu et al. [2005] predicted a total dust flux $(0.1-20 \mu \mathrm{m})$ of $1684 \mathrm{Tg} \mathrm{yr}^{-1}$, which is on the lower end of predictions from ten different models $\left(820-5102 \mathrm{Tg}^{-1}\right)$. Liu et al. [2005] carried out an evaluation of the aerosol simulation against in situ observations from 15 oceanic sites. In regions of the southern hemisphere, which are influenced by dust emissions from Patagonian (Palmer Antarctic) and Australian (Cape Grim, Norfolk, New Caledonia) deserts, Liu et al. [2005] found that the model reproduces the seasonal cycle of dust concentration, although the dust concentration was underpredicted during the austral summer. In the Northern Hemisphere, the model reproduced the concentrations and seasonal cycles of the African dust sampled at Izaña Tenerife, Barbados, and Bermuda; the model overpredicted, however, the concentration in August at Izaña and underpredicted the concentration in July and August at Bermuda by a factor of two. Further details on the GMI framework can be found in Barahona et al. [2010a, 2011].

\subsection{Aerosol Distribution}

[9] The concentration of particles that can experience hygroscopic growth is given as an input from the aerosol module to the cloud droplet formation parameterization and is distributed in four aerosol types: fossil fuel (sulfate, organic mass, and black carbon), biomass burning (organic mass and black carbon), marine (natural sulfate and sea salt), and mineral dust. Fossil fuel, biomass burning, and marine aerosols are assumed to follow KT for CCN activation, whereas mineral dust is assumed to be insoluble and follow FHH-AT. Particles within each aerosol type are internally mixed and assumed to follow a prescribed number size distribution function (Table 1). Fossil fuel aerosols are represented by a size distribution given by Chuang et al. [1997] and Radke et al. [1988]. The particle size distributions for biomass burning aerosols are based on measurements by Anderson et al. [1996]. Marine aerosols are represented by a size distribution proposed by Lance et al. [2004] and mineral dust particles are assumed to follow the size distribution by d'Almeida et al. [1987]. The number concentration of each aerosol type (e.g., fossil fuel) is given by $N=m_{t o t} /\left(V \rho_{t o t}\right)$, where $m_{t o t}$ is the total mass concentration (across size bins) of the aerosol type, $V$ is the volume of a particle with dry diameter equal to $d_{g}$, and $\rho_{t o t}$ is the density of the aerosol type given by $\rho_{\text {tot }}=m_{\text {tot }} / \sum_{i=1}^{n}\left(m_{i} / \rho_{i}\right)$. Here $m_{i}$ is the mass concentration of each component within the aerosol type (e.g., sulfate, $\mathrm{OC}, \mathrm{BC}$ ), $\rho_{i}$ is its density, and $n$ is the number of aerosol types.

\subsection{Cloud Droplet Formation Parameterization}

[10] Calculation of CDNC for particles following FHH-AT is performed in two conceptual steps, one involving the determination of the "CCN spectrum" (i.e., the number of $\mathrm{CCN}$ that can activate to form droplets at a certain level of supersaturation), and another one determining the maximum supersaturation, $s_{\max }$, that develops in the ascending cloudy parcels used to represent droplet formation in the general circulation model (GCM). The CDNC is then just the value of the CCN spectrum at $s_{\max }$.

[11] The "CCN spectrum," $F^{s}(s)$, is computed following Kumar et al. [2009b] and assumes that particles can be described either by KT or FHH-AT. $F^{s}(s)$ for an external mixture of lognormal particle size distributions is given by:

$$
F^{s}(s)=\int_{0}^{s} n^{s}(s) d s=\sum_{i=1}^{n_{m}} \frac{N_{i}}{2} \operatorname{erfc}\left[-\frac{\ln \left(\frac{s_{g, i}}{s}\right)}{x \sqrt{2} \ln \left(\sigma_{i}\right)}\right]
$$

where $s$ is the level of water vapor supersaturation, $s_{g, i}$ is the critical supersaturation of the particle with a diameter equal to the geometric mean diameter of the mode $i, \sigma_{i}$ is the geometric standard deviation for mode $i$, and $x$ is an exponent that depends on the activation theory used. For modes following Köhler theory, $x=-3 / 2$ [Fountoukis and Nenes, 2005], while for particles following FHH theory, $x$ depends on $A_{F H H}$ and $B_{F H H}$ [Kumar et al., 2009b]. The adsorption parameter $B_{F H H}$ expresses the long range interactions of adsorbed water layers with the dust surface. The smaller the value of $B_{F H H}$, the greater the distance from the dust surface for which attractive forces are present. $A_{F H H}$ primarily represents the interaction between the first water monolayer and the dust surface. $A_{F H H}$ and $B_{F H H}$ are compound-specific and determined experimentally, with $A_{F H H}$ typically ranging from 0.1-3.0, and $B_{F H H}$ ranging from 0.5-3.0 [Sorjamaa and Laaksonen, 2007]. Kumar et al. [2011b] tested a wide range of fresh unprocessed regional dust samples and minerals and found that one set of the FHH parameters 
$\left(A_{F H H}=2.25 \pm 0.75, B_{F H H}=1.20 \pm 0.10\right)$ can adequately reproduce the measured $\mathrm{CCN}$ activity for all dust types considered.

[12] The maximum supersaturation, $s_{\max }$, in the ascending parcel is calculated from an equation that expresses the supersaturation tendency in cloudy air parcels, which at the point of maximum supersaturation becomes [Barahona and Nenes, 2007; Nenes and Seinfeld, 2003],

$$
\frac{2 a V}{\pi \gamma \rho_{w}}-G s_{\max } I\left(0, s_{\max }\right)=0
$$

where $V$ is the updraft velocity, $\rho_{w}$ is the density of water, and $a, \gamma, G$ are parameters defined in Barahona and Nenes [2007]. Once $s_{\max }$ is determined by numerically solving equation (2), $N_{d}=F\left(s_{\max }\right)$ from equation (1).

[13] In equation (2), $I\left(0, s_{\max }\right)$ is known as the "condensation integral" [Barahona and Nenes, 2007; Barahona et al., 2010b; Kumar et al., 2009b] and it expresses the condensational depletion of supersaturation upon the growing droplets at the point of $s_{\max }$ in the cloud updraft. It is expressed as the sum of three terms [Kumar et al., 2009b],

$$
I\left(0, s_{\max }\right)=I_{K}\left(0, s_{\max }\right)+I_{F H H}\left(0, s_{\max }\right)+I_{G C C N}\left(0, s_{\max }\right)
$$

The first term in the right hand side of equation (3) gives the contribution from particles that follow Köhler theory, $I_{K}\left(0, s_{\max }\right)$, the second one from particles that follow the FHH theory, $I_{F H H}\left(0, s_{\max }\right)$, and the third one accounts for the effect of the very large and giant $\mathrm{CCN}$ (neglected by the other two terms). Using the population splitting approach of Nenes and Seinfeld [2003], $I_{K}\left(0, s_{\max }\right)$ is calculated as: $I_{K}\left(0, s_{\max }\right)=I_{K, 1}\left(0, s_{\text {part }}\right)+I_{K, 2}\left(s_{\text {part }}, s_{\max }\right)$, where $I_{K, 1}\left(0, s_{\text {part }}\right)$ and $I_{K, 2}\left(s_{\text {part }}, s_{\max }\right)$ are presented by Fountoukis and Nenes [2005] or Kumar et al. [2009b]. The partition supersaturation, $s_{\text {part }}$, separates two CCN populations, one (expressed by $\left.I_{K, 2}\left(s_{\text {part }}, S_{\text {max }}\right)\right)$ for which droplets experience negligible growth beyond the critical diameter $\left(s_{c} \approx s_{\max }\right)$, and another one (expressed by $\left.I_{K, 1}\left(0, s_{\text {part }}\right)\right)$ for which droplet growth is much larger than the critical diameter $\left(s_{c} \ll s_{\max }\right)$. In equation (3), $I_{F H H}\left(0, s_{\max }\right)$ represents the contribution of FHH particles to the condensation integral [Kumar et al., 2009b].

[14] If dust particles contain a substantial fraction of soluble material, the critical supersaturation is determined using the "unified dust activation framework" of Kumar et al. [2011b], which involves determining the maximum of the relevant equilibrium curve describing an aerosol particle (consisting of insoluble core with a soluble coating) in equilibrium with the surrounding water vapor:

$$
s=\frac{4 \sigma M_{w}}{R T \rho_{w} D_{P}}-\frac{\varepsilon_{s} D_{d r y}^{3} \kappa}{\left(D_{P}^{3}-\varepsilon_{i} D_{d r y}^{3}\right)}-A_{F H H}\left(\frac{D_{P}-\varepsilon_{i}^{1 / 3} D_{d r y}}{2 D_{w}}\right)^{-B_{F H H}}
$$

where $D_{p}$ is the wet equilibrium diameter, $D_{d r y}$ is the particle dry diameter, $\varepsilon_{i}$ is the insoluble volume fraction, $\varepsilon_{s}$ is the soluble volume fraction, and $\kappa$ is the hygroscopicity of the soluble fraction. The exponent $x$ in the case of aged dust particles lies somewhere between the KT and FHH-AT limits, and is determined (as described by Kumar et al. [2011b]) by performing a power law fit between $s_{c}$ and
$D_{d r y}$ determined from equation (4). Given that dust is considered to be a separate population from other aerosol types, application of the unified dust activation framework in the Kumar et al. [2009b] parameterization is carried out by replacing the $x, s_{\mathrm{c}}$ normally computed by FHH-AT with those of the unified framework.

[15] Finally, $I_{G C C N}\left(0, s_{\max }\right)$ accounts for the effect of the very large and giant $\mathrm{CCN}$ on the condensation rate and is presented by Barahona et al. [2010b] as:

$$
\begin{aligned}
I_{G C C N}\left(0, s_{\max }\right)= & \sum_{i=1}^{n_{m}}\left(\frac{N_{i}}{2} D_{g, i} \exp \left[\left(\frac{x}{\sqrt{2}}\right)^{2} \ln ^{2} \sigma_{i}\right]\right. \\
& \left.\cdot \operatorname{erfc}\left(-\frac{1}{x \sqrt{2} \ln \sigma_{i}} \ln \frac{D_{p_{\min }}}{D_{g, i}}+\frac{x}{\sqrt{2}} \ln \sigma_{i}\right)\right)
\end{aligned}
$$

where $D_{p_{\min }}$ is the wet equilibrium diameter of the smallest particle that activates (i.e., for which $s_{c}=s_{\max }$ ) and $D_{g, i}$ is the geometric mean diameter of mode $i$. For giant nuclei following Köhler theory, $D_{p_{\min }}=2 A /\left(3 \sqrt{3} s_{\text {part }}\right)$, where $A=4 \sigma M_{w} / R T \rho_{w}$, and represents the boundary between particles that experience significant growth after activation and those that are strongly kinetically limited [Barahona et al., 2010b; Nenes and Seinfeld, 2003]. Giant nuclei following FHH theory do not grow significantly after activation and therefore are kinetically limited by the inertial mechanism [Nenes et al., 2001]; indeed, $D_{c} / D_{d r y}<2$ for most atmospherically relevant combinations of $A_{F H H}$ and $B_{F H H}$ [Kumar et al., 2009b], where $D_{c}$ is the critical wet droplet diameter. $D_{p_{\min }}$ is calculated at $s_{\text {part }}$, given by the solution of equation (4).

\subsection{Model Application}

[16] The model results presented here are based on $1 \mathrm{yr}$ simulations and the first month of each simulation has been excluded in order to limit the effect the initial conditions have on the results (simulations with longer startup periods did not substantially affect the simulation results). The meteorological fields used in the simulations were taken from the Goddard Institute for Space Studies version II (GISS II) GCM [Koch and Rind, 1998; Rind and Lerner, 1996], which includes a slab (Q-flux) ocean model to represent the ocean-atmospheric coupling. The data set spans over $1 \mathrm{yr}$ and represents the period from March 1997 to February 1998. The horizontal resolution is $4^{\circ}$ latitude by $5^{\circ}$ longitude. The vertical resolution is 23 vertical layers (from surface to $0.017 \mathrm{hPa}$ ). Meteorological information was updated at $3 \mathrm{~h}$ intervals and archived for the year of simulation.

[17] Parameters used by the cloud droplet formation parameterization in this study include the aerosol size distributions (section 2.1), an effective water vapor uptake coefficient of 0.06 [Fountoukis et al., 2007], the updraft velocity representative of typical stratocumulus clouds and constrained using observations, $V=0.3 \mathrm{~m} \mathrm{~s}^{-1}$ over land, and $V=0.15 \mathrm{~m} \mathrm{~s}^{-1}$ over ocean [Chuang et al., 2000; Guibert et al., 2003; Meskhidze et al., 2005b], and "base case" FHH adsorption parameters, $A_{F H H}=2.25$ and $B_{F H H}=1.2$ [Kumar et al., 2011b]. Updraft velocity varies significantly within a GCM grid cell and between clouds; however, grid-average CDNC for stratiform clouds can be calculated by computing $\mathrm{CDNC}$ at a "characteristic" vertical velocity 

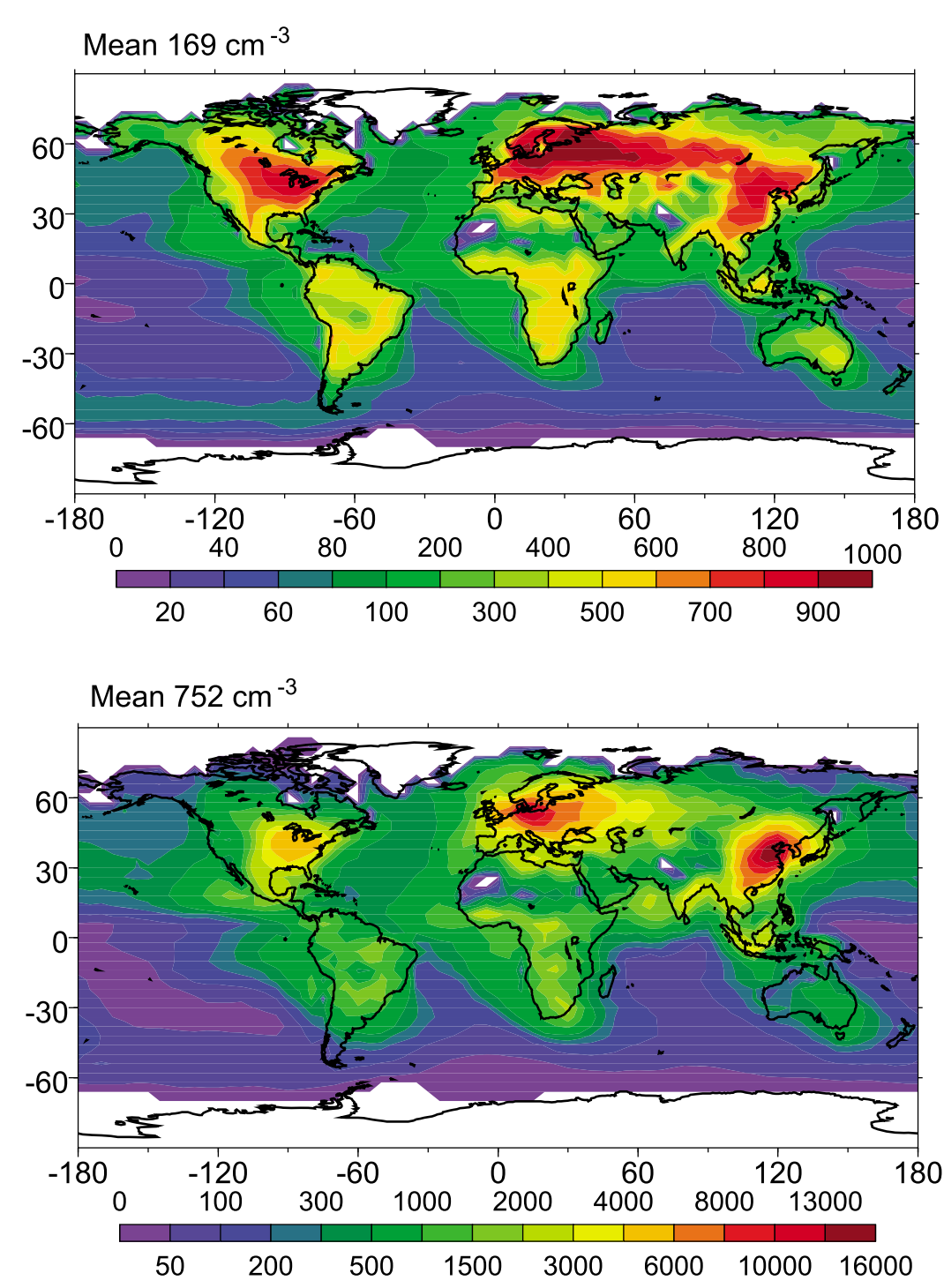

Figure 1. Predicted annual (top) mean cloud droplet and (bottom) cloud condensation nuclei (CCN) at $0.2 \%$ supersaturation concentrations $\left(\mathrm{cm}^{-3}\right)$ for the lowest cloud-forming level (960 mbar). White represents cloud-free areas.

[Morales and Nenes, 2010], which is very close to the average updraft velocity. Meskhidze et al. [2005b] and Fountoukis et al. [2007] showed that using the average updraft gives optimal CDNC closure in cumulus and stratocumulus clouds sampled in a variety of field campaigns.

\section{Results}

\subsection{Overview of Model Predictions}

[18] The predicted annual mean $\mathrm{CCN}$ at $0.2 \%$ supersaturation and cloud droplet number concentrations for the lowest cloud-forming level (at $960 \mathrm{mbar}$ ) are shown in Figure 1. CDNC is referred to the number concentration of droplets nucleated in-cloud and represents an upper limit since the model does not account for droplet depletion by collision, coalescence and collection. As expected, higher CDNC concentrations (up to $1000 \mathrm{~cm}^{-3}$ ) are predicted over the midlatitudes of the Northern Hemisphere (i.e., over China, Europe, and eastern U.S.; Figures 1a and 2), consistent with the high concentration levels of $\mathrm{CCN}$ associated with industrialized regions (Figure 1b). Over the continents of the Southern Hemisphere, large CDNC values (up to $600 \mathrm{~cm}^{-3}$ ) occur over regions affected by biomass burning in South America and Africa. The lower continental CDNC values are predicted over the arid areas of the Sahara and Gobi deserts (up to $300 \mathrm{~cm}^{-3}$ ). Over oceans, CDNC is increased up to $300 \mathrm{~cm}^{-3}$ by continental aerosol transported by the trade winds off the subtropical west coasts of Africa and America, and westerlies in midlatitude east coasts of North America and Asia (Figure 1) [Minnis et al., 1992; Prospero et al., 1983]. In contrast to the Northern Hemisphere, lower cloud droplet number concentrations are found over the cleaner remote oceans of the Southern Hemisphere and in the polar regions (Figure 1a, 1b). In these regions, CDNC is predicted to be up to $40 \mathrm{~cm}^{-3}$. Over the Southern Ocean, larger CDNC values are predicted (up to $80 \mathrm{~cm}^{-3}$ ) due to the enhanced production of sulfate from dimethyl sulfide (DMS) oxidation, and the high concentrations of sea salt, which is lofted by winds associated with the Antarctic 
Mean $120 \mathrm{~cm}^{-3}$

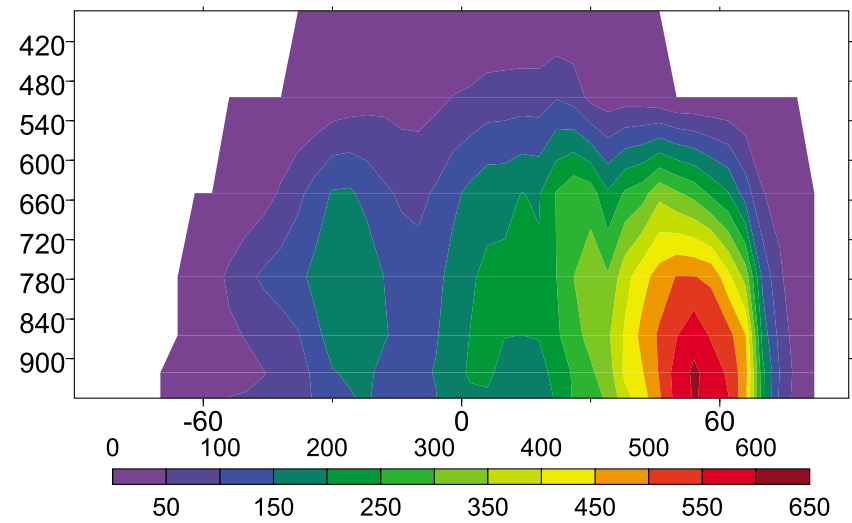

Figure 2. Predicted zonal annual mean cloud droplet number concentration $\left(\mathrm{cm}^{-3}\right)$. White areas correspond to noncloud-forming regions.

circumpolar vortex that flows eastward around Antarctica. Predicted CDNC decreases with altitude over the polluted areas of the Northern Hemisphere caused by a decrease in aerosol concentration (Figure 2). Over the tropics, however, CDNC increases until 865 mbar, influenced by long-range transport of polluted air masses, and then decreases. The global mean CDNC is predicted to be $169 \mathrm{~cm}^{-3}, 177 \mathrm{~cm}^{-3}$, $188 \mathrm{~cm}^{-3}, 181 \mathrm{~cm}^{-3}$, and $128 \mathrm{~cm}^{-3}$ at $960,920,865,780$, and 650 mbar, respectively. These values are within the limits of simulated CDNC published in the literature. Merikanto et al. [2010] obtained a yearly global average CDNC of 211$240 \mathrm{~cm}^{-3}$ from model runs at $300-1000 \mathrm{~m}$ above ground level. Chen et al. [2010] reported a CDNC value of $189 \mathrm{~cm}^{-3}$ at $972 \mathrm{mbar}$ and $122 \mathrm{~cm}^{-3}$ at $850 \mathrm{mbar}$. Penner et al. [2006] found the CDNC ranging from $119 \mathrm{~cm}^{-3}$ to $159 \mathrm{~cm}^{-3}$ near 850 mbar. Barahona et al. [2011] found the global mean CDNC ranging from $96 \mathrm{~cm}^{-3}$ to $103 \mathrm{~cm}^{-3}$ at $850 \mathrm{mbar}$ depending on the climatological meteorological fields used. Finally, Leibensperger et al. [2011] report a global mean CDNC of $83 \mathrm{~cm}^{-3}$ at 850 mbar.

\subsection{Model Evaluation}

[19] The predicted cloud droplet number concentration is compared against observational data from continental, polluted marine, and clean marine regions around the world (Figure 3). The predictions reflect aerosol distributions in an average climate state; given that the observations span over a decade, we expect a spatial and seasonal correspondence with the predictions. The summary of this comparison is depicted in Table 2 and Figure 4. Over clean marine regions,

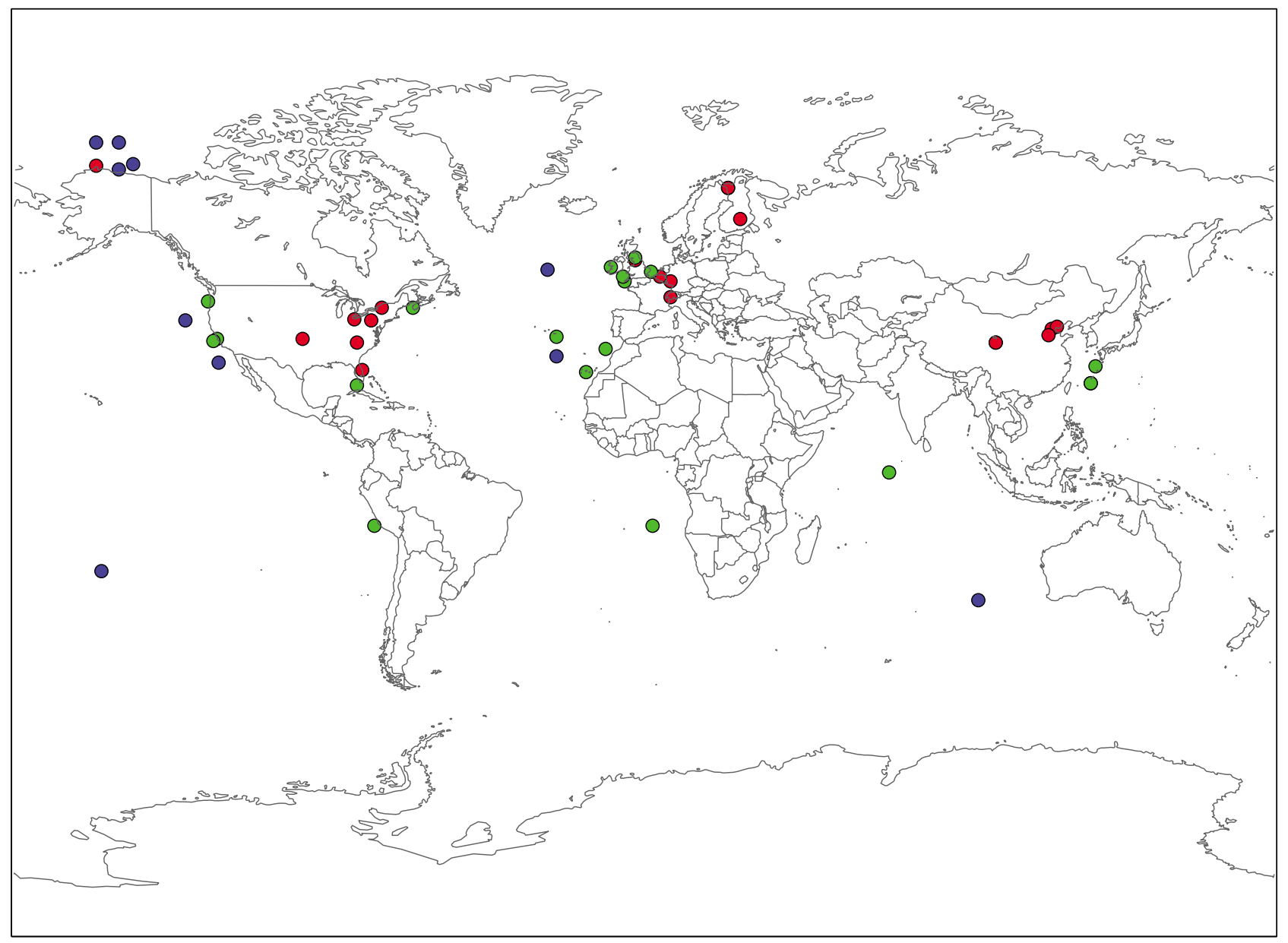

Figure 3. Location of observational data used for the evaluation of model predictions. Continental, polluted marine, and clean marine regions are represented by red, green, and blue symbols, respectively. 


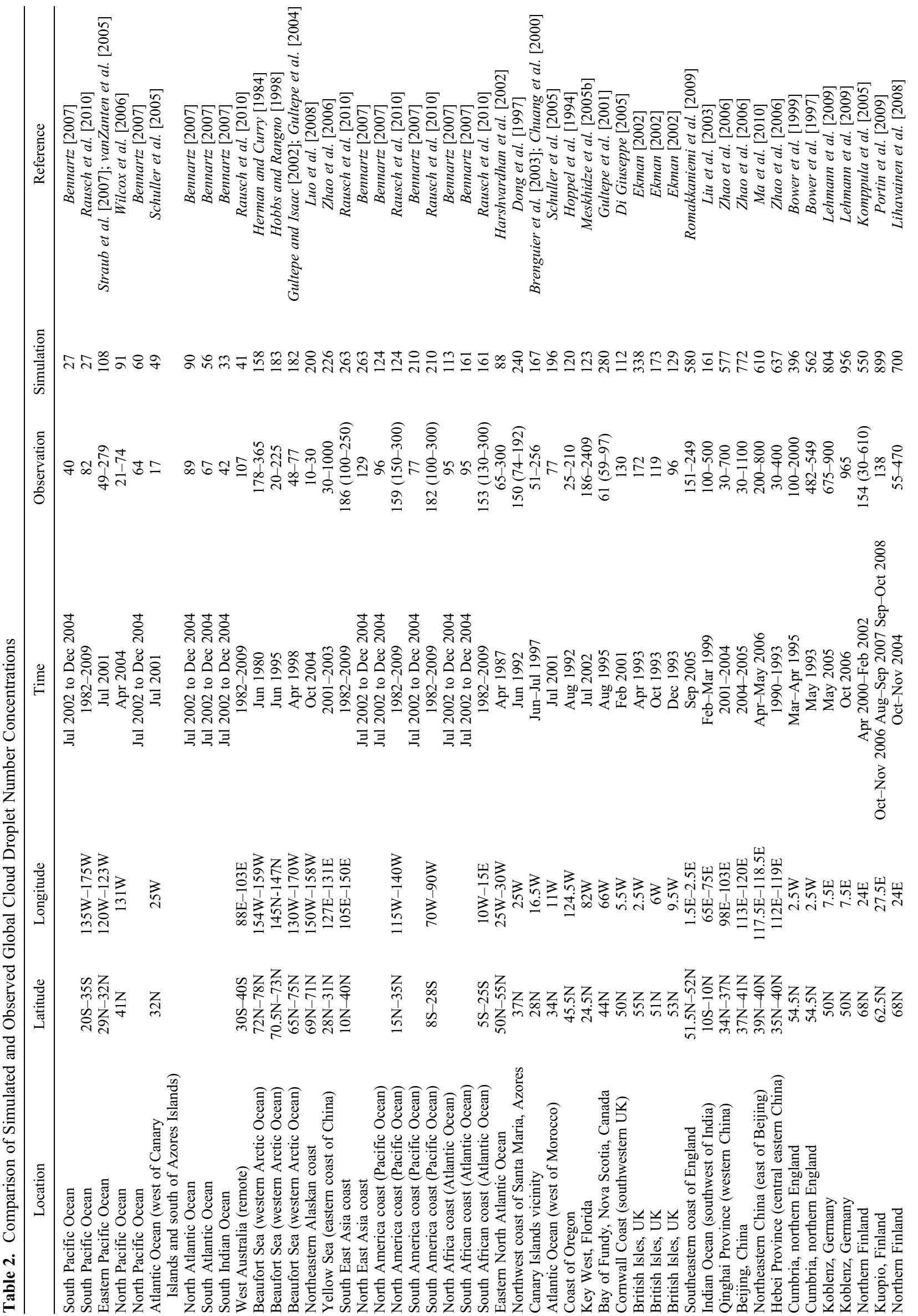




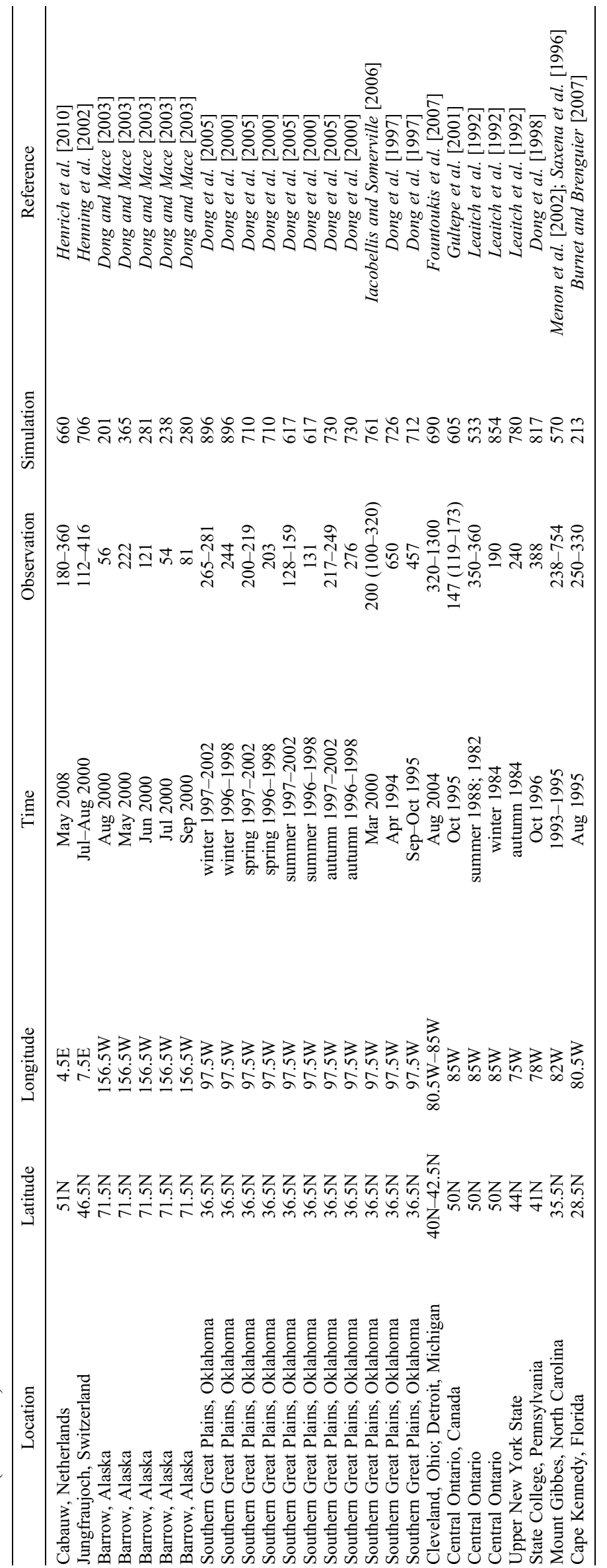




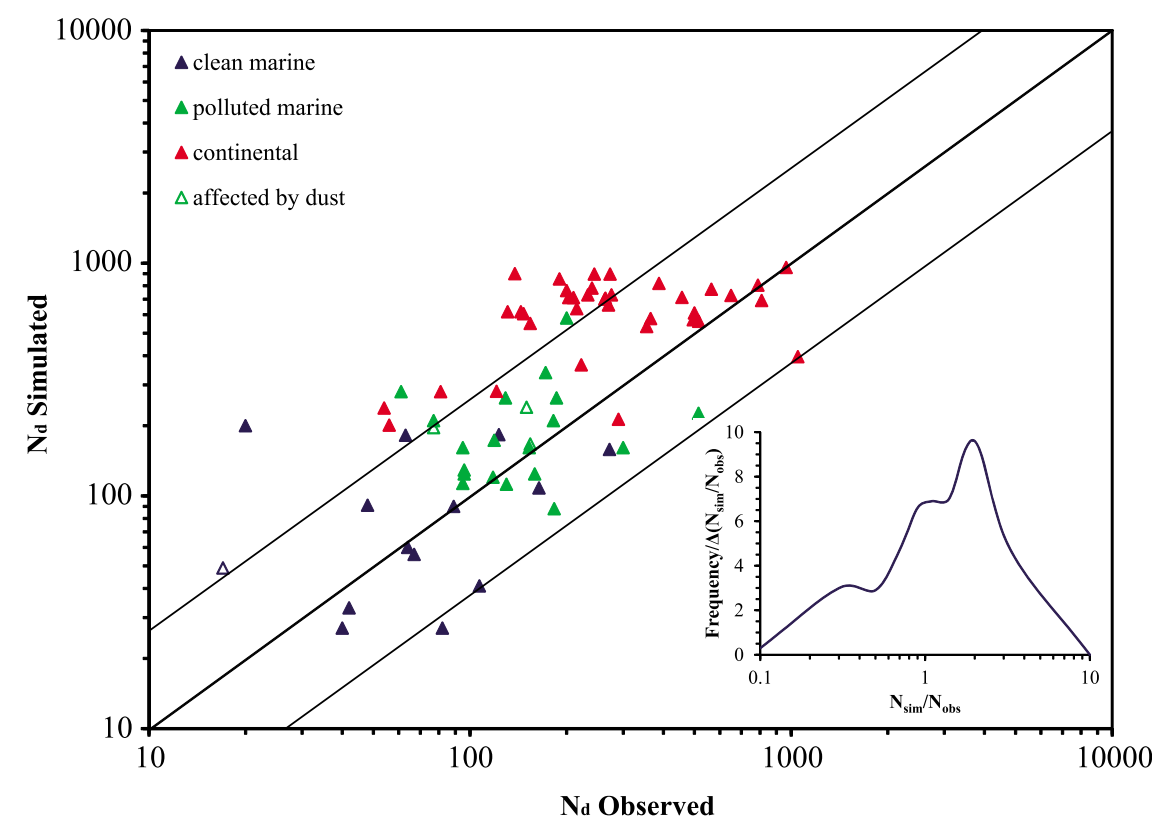

Figure 4. Comparison of simulated and observed global cloud droplet number concentrations $\left(\mathrm{cm}^{-3}\right)$. Open symbols correspond to dust affected regions. Also shown are the $1: 1, \pm 50 \%$ lines, and the probability distribution of the ratio of the simulated CDNC to the observed CDNC (inset plot).

concentrations of $27 \mathrm{~cm}^{-3}$ (South Pacific) to $108 \mathrm{~cm}^{-3}$ (Eastern Pacific) are predicted; this agrees with retrieved CDNC values mostly to within $50 \%$, ranging from $40 \mathrm{~cm}^{-3}$ (South Pacific [Bennartz, 2007]) to $279 \mathrm{~cm}^{-3}$ (Eastern Pacific [Straub et al., 2007; vanZanten et al., 2005]). Larger underestimation is found over the remote area west of Australia $\left(41 \mathrm{~cm}^{-3}\right.$ versus $107 \mathrm{~cm}^{-3}$ reported by Rausch et al. [2010]). Moreover, over the Western Arctic Ocean, the predicted CDNC range from $158 \mathrm{~cm}^{-3}$ to $200 \mathrm{~cm}^{-3}$. This agrees well with available observations [Herman and Curry, 1984; Hobbs and Rangno, 1998], but is considerably overpredicted over the North Pacific and Arctic Ocean [Gultepe and Isaac, 2002; Gultepe et al., 2004; Luo et al., 2008].

[20] The predicted CDNC increases to $88-580 \mathrm{~cm}^{-3}$ over polluted marine regions close to coasts. The highest observed CDNC value is over the Yellow Sea (eastern coast of China). In particular, Zhao et al. [2006] reported measured values ranging from $30 \mathrm{~cm}^{-3}$ to $1000 \mathrm{~cm}^{-3}$. The predicted CNDC is $226-263 \mathrm{~cm}^{-3}$ which is relatively high compared to satellite retrievals (100-250 $\mathrm{cm}^{-3}$ reported by Bennartz [2007] and Rausch et al. [2010]). The model predictions are in better agreement with these studies over North America coast (124 $\mathrm{cm}^{-3}$ versus 96-300 $\mathrm{cm}^{-3}$ ), South America coast $\left(210 \mathrm{~cm}^{-3}\right.$ versus $\left.77-300 \mathrm{~cm}^{-3}\right)$, and Africa $\left(113-161 \mathrm{~cm}^{-3}\right.$ versus $95-300 \mathrm{~cm}^{-3}$ ). Over Atlantic Ocean, the CDNC predictions range between $88 \mathrm{~cm}^{-3}$ (eastern north Atlantic) and $240 \mathrm{~cm}^{-3}$ (Santa Maria, Azores). This is well within the observed values over that region $\left(65-300 \mathrm{~cm}^{-3}\right.$ [Brenguier et al., 2003; Chuang et al., 2000; Dong et al., 1997; Harshvardhan et al., 2002; Schüller et al., 2005]).

[21] The predicted CDNC over continental regions ranges between $201 \mathrm{~cm}^{-3}$ (Barrow, AK) and $956 \mathrm{~cm}^{-3}$ (Koblenz, Germany) compared to observed values of up to $2000 \mathrm{~cm}^{-3}$ (Cumbria, North England [Bower et al., 1999]). In Asia, predicted values range from $577 \mathrm{~cm}^{-3}$ over Western China (observed $30-700 \mathrm{~cm}^{-3}$ [Zhao et al., 2006]) to $772 \mathrm{~cm}^{-3}$ over Beijing (observed $30-1000 \mathrm{~cm}^{-3}$ [Zhao et al., 2006]). In Europe, the model predicts a lower concentration $\left(396 \mathrm{~cm}^{-3}\right)$ over North England, where there are the highest observations (100-2000 $\mathrm{cm}^{-3}$ [Bower et al., 1999]). The highest CDNC are predicted over Koblenz, Germany (804$956 \mathrm{~cm}^{-3}$ ) and are in good agreement with observations (675-965 $\mathrm{cm}^{-3}$ [Lehmann et al., 2009]). Over Finland, the model tends to overpredict $\mathrm{CDNC}$, with values ranging from $550 \mathrm{~cm}^{-3}$ to $899 \mathrm{~cm}^{-3}$ versus $30 \mathrm{~cm}^{-3}$ to $610 \mathrm{~cm}^{-3}$ [Komppula et al., 2005; Lihavainen et al., 2008; Portin et al., 2009]. Finally, over North America, the predicted CDNC range from $201 \mathrm{~cm}^{-3}$ over Alaska (observed of 54-222 $\mathrm{cm}^{-3}$ [Dong and Mace, 2003]) to $896 \mathrm{~cm}^{-3}$ over Oklahoma (observed of $100-650 \mathrm{~cm}^{-3}$ [Dong et al., 2005, 1997, 2000; Iacobellis and Somerville, 2006]). The observations range from $54 \mathrm{~cm}^{-3}$ (Barrow, AK [Dong and Mace, 2003]) to $1300 \mathrm{~cm}^{-3}$ (Cleveland, OH, and Detroit, MI [Fountoukis et al., 2007]).

[22] Overall, the model is in reasonably good agreement with observations over both clean and polluted marine regions as well as over regions that are relatively close to dust sources (e.g., Canary Islands). More precisely, $67 \%$ of the CDNC predictions over those regions diverge less than $50 \%$ from available measurements (Figure 4). The model tends to overpredict the CDNC compared to observed data from continental regions (Figure 4). Considering the influence of droplet collision and coalescence processes may, in part, reduce prediction biases. Given however that dust is not expected to be a significant contributor to $\mathrm{CCN}$ number in these regions, we do not anticipate the overprediction bias to affect conclusions.

\subsection{Effect of Dust on CCN and CDNC}

[23] The contribution of insoluble particles to cloud droplet formation is potentially most important in areas close to mineral dust sources. These areas may not always be associated with extensive cloud cover; to account for this, 


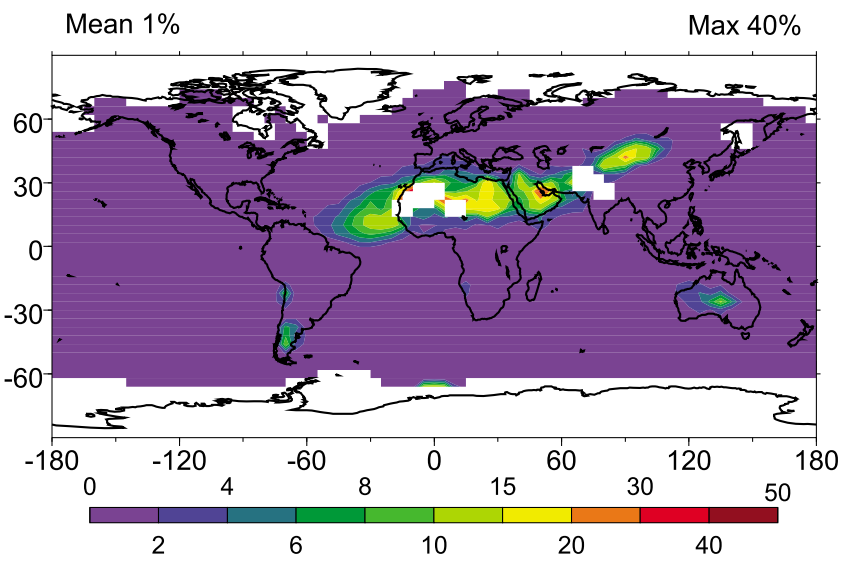

Figure 5. Predicted annual mean contribution (\%) of mineral dust to particle number concentrations for the lowest cloud-forming level (960 mbar). White represents areas that are free of warm clouds throughout the year.

CDNC are calculated only in cells for which warm clouds are present (i.e., cloud water is present, and cloud top temperature exceeds 263K). Mineral dust effects on CDNC depend on the predicted contribution of mineral dust to total aerosol number concentration, as the available aerosol budget is the main factor driving the $\mathrm{CCN}$ population. Close to deserts, the dominant aerosol constituent ( $80-99 \%$ by mass) is mineral dust with the rest of the aerosols consisting of soluble materials, such as sulfate, organic carbon, and sea salt from long-range transport. However, these soluble aerosols are small in size compared to mineral dust and therefore can contribute substantially to aerosol number and $\mathrm{CCN}$ concentrations. The predicted contribution of mineral dust to particle number concentrations is presented in Figure 5. The contribution of dust to the total aerosol number concentration is small on a global scale $(\sim 1 \%)$, but regionally can be large, especially during dust episodes and their long-range transport (Figure 5). The largest contribution (up to $40 \%$ ) is seen over North Africa and Asia (Arabian Peninsula and Gobi Desert) while mineral dust from South America (Patagonian Desert) and Australian deserts also contributes to the total aerosol number concentration (10-15\%). These contributions represent an average climatology but will vary significantly, both seasonally and interannually.

[24] To investigate the potential importance of dust on cloud droplet formation, the predicted contribution of dust to total $\mathrm{CCN}$ is shown in Figure 6 for moderate $(0.2 \%)$ and high $(0.4 \%)$ supersaturations. The contribution of mineral dust to the $\mathrm{CCN}$ concentration decreases with decreasing supersaturation as insoluble aerosols are less hygroscopic and they need higher supersaturations in order to activate compared to soluble particles. Nevertheless, dust particles are coarser than soluble aerosols and therefore, if coated with hygroscopic material, they can potentially activate at lower supersaturations than smaller anthropogenic particles. At $0.2 \%$ supersaturation, the contribution of mineral dust to the total CCN concentration is up to $30 \%$ while at $0.4 \%$ supersaturation the contribution increases to $35 \%$. In both cases, the maximum predicted contribution occurred on the eastern part of the Arabian Peninsula.
[25] The contribution of dust to CNDC is computed directly from the parameterization output, as the activation fraction for each aerosol mode is known. The predicted $s_{\max }$ in clouds forming in these dusty areas remains low $(\sim 0.1 \%$ on average), hence mineral dust contributes up to $23.8 \%$ of the CDNC (Figure 7). Moreover, allowing dust to act as $\mathrm{CCN}$ resulted in a relatively significant decrease of $s_{\max }$ over Western Saharan (30\%) and Patagonian (10\%) deserts. Over the remaining arid areas (e.g., Gobi and Australian deserts) the decrease in $s_{\max }$ is less important (less than $5 \%$ ). Mineral dust also has a small contribution to the annual average predicted CDNC across the Atlantic Ocean, as far as the Caribbean Sea (up to $10 \%$ near the North African coast). This contribution can be significantly larger during dust episodes. The peak contribution of mineral dust to CDNC across the Atlantic Ocean is predicted during the month of February (15\%). The greatest seasonal variability of the contribution of mineral dust to CDNC is predicted downstream of the Patagonia Desert, where it varies from 2\% during May to $40 \%$ during February.

\section{Sensitivity Analyses}

[26] Dust-relevant inputs in the CDNC parameterization, other than dust concentration, include $A_{F H H}, B_{F H H}$ and the
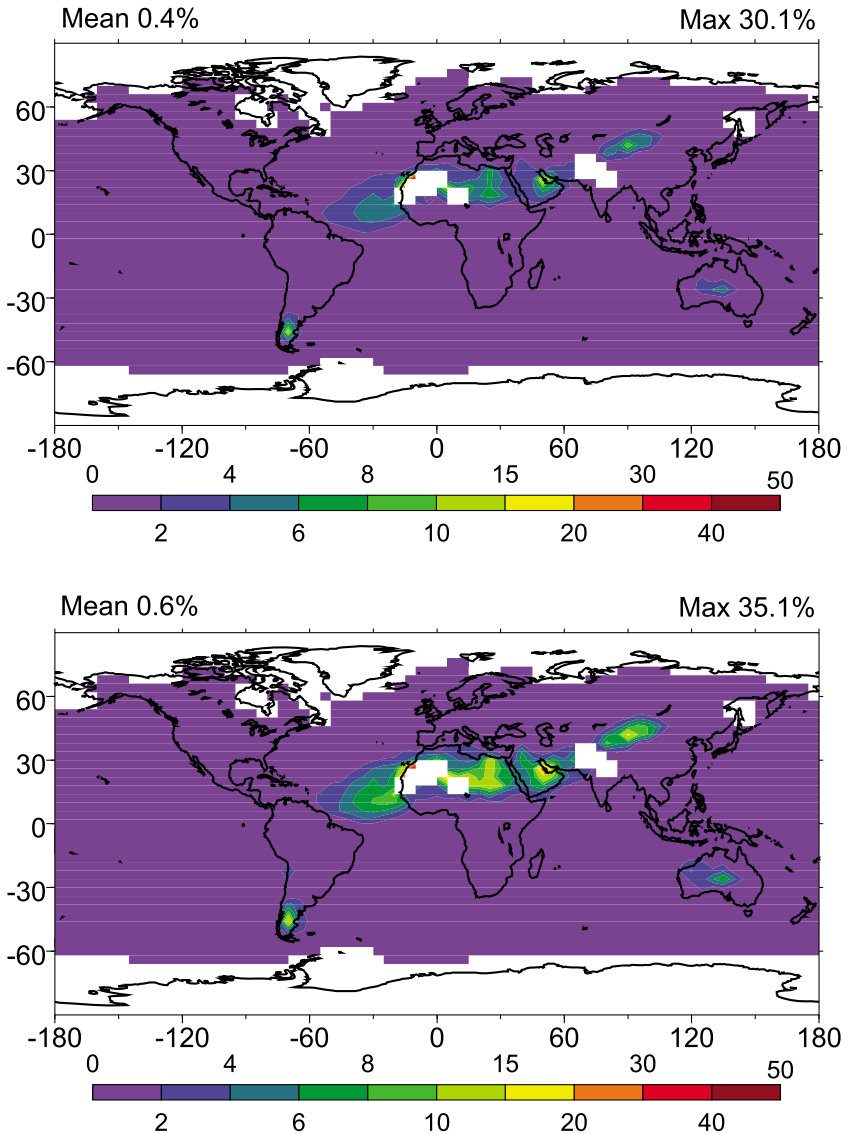

Figure 6. Predicted annual mean contribution (\%) of mineral dust to total CCN for (top) $0.2 \%$ and (bottom) $0.4 \%$ supersaturation for the lowest cloud-forming level (960 mbar). White represents areas that are free of warm clouds throughout the year. 

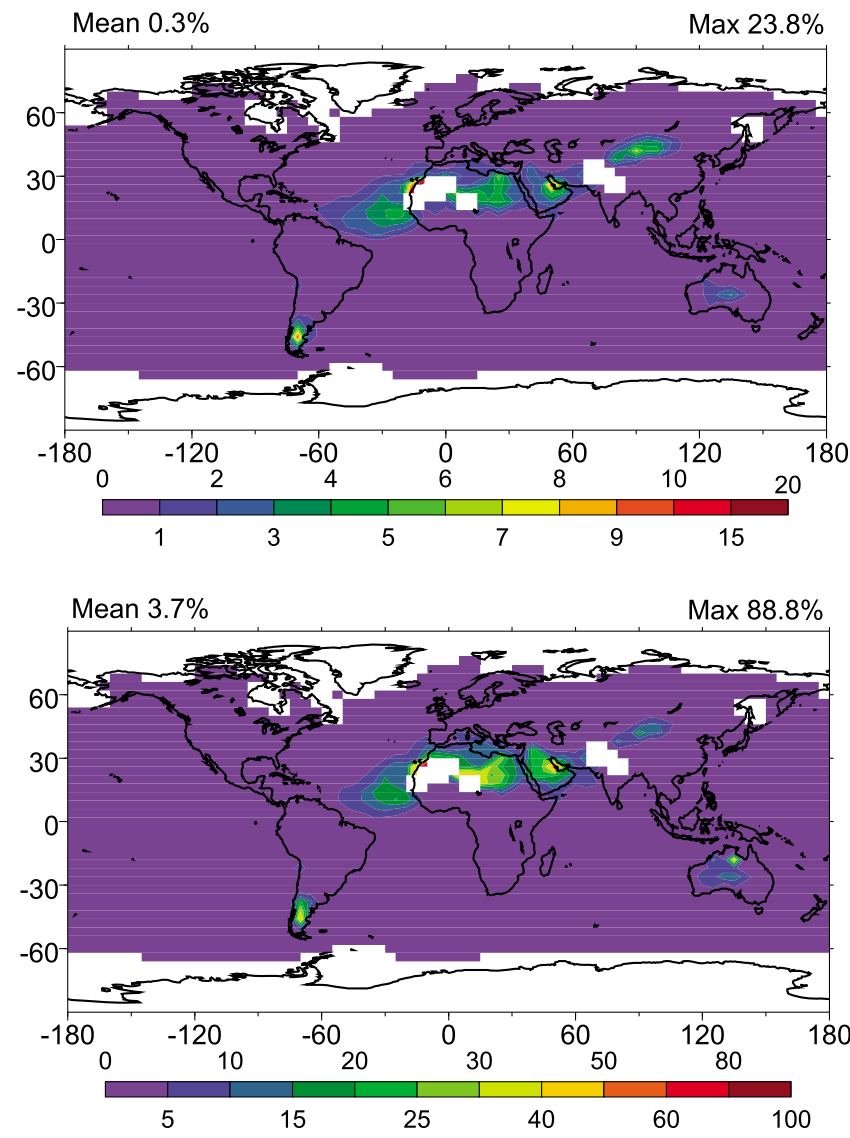

Figure 7. Predicted annual mean mineral dust contribution (\%) to cloud droplet number concentration for the lowest cloud-forming level (960 mbar) by using (top) present-day and (bottom) preindustrial anthropogenic emissions. White represents areas that are free of warm clouds throughout the year.

size distribution of dust particles. To investigate the impact of uncertainty in these inputs on the predicted effect of mineral dust on CDNC, five sensitivity simulations were conducted. First, we carry out simulations using an alternate size distribution (Table 1), measured over Niger during January 2006 [Chou et al., 2008]. Second, we vary the sensitivity to $A_{F H H}$ and $B_{F H H}$ parameters using limits reported by Kumar et al. [2011b]. In particular, the set of parameters used in these simulations are: $A_{F H H}=2.25$, $B_{F H H}=1.1 ; A_{F H H}=2.25, B_{F H H}=1.3 ; A_{F H H}=1.5, B_{F H H}=$ 1.2 ; and $A_{F H H}=3.0, B_{F H H}=1.2$. Finally, two additional sensitivity simulations were conducted to test the effect of anthropogenic emissions and atmospheric aging on mineral dust contribution to CDNC.

\subsection{Sensitivity of CDNC and Total Aerosol Number to Size Distribution of Dust}

[27] The size distribution used for the sensitivity test tends to distribute more mineral dust mass onto larger size particles than in the base case scenario. As a result, the number concentration of mineral dust is lower; compared to the base case simulation, the contribution of insoluble aerosols to annual mean total aerosol number concentration is found to be $45 \%$ lower (not shown). As expected, this significant change in the number of available insoluble particles reduces the contribution of dust particles to CDNC. The fraction of the droplets coming from the activation of insoluble particles is on average $23 \%$ lower than the base case simulation in areas with high concentration of dust (Table 3). Over remote areas of the Atlantic Ocean, the contribution of mineral dust to $\mathrm{CDNC}$ is $40 \%$ lower than the base case simulation (not shown). The base case simulation predicted that mineral dust can contribute to cloud droplet formation over a wide area that extended thousands of miles from its sources (e.g., the tropical Atlantic Ocean), in contrast to the sensitivity case simulation where the mineral dust effect on CDNC is predicted in a relatively limited area close to its sources (i.e., deserts).

\subsection{Sensitivity of CDNC to $\boldsymbol{A}_{F H H}$ and $B_{F H H}$ Parameters}

[28] Lower values of the $B_{F H H}$ parameter corresponds to a more hydrophilic particle and largely determines the existence and values of the particle critical supersaturation, $s_{\mathrm{c}}$ [Kumar et al., 2009b]. $A_{F H H}$ also affects the particle CCN activity, but to a lesser extent than $B_{F H H}$. Kumar et al. [2011b] showed that one set of the FHH parameters $\left(A_{F H H}=2.25 \pm\right.$ $\left.0.75, B_{F H H}=1.20 \pm 0.10\right)$ encompasses the range of hygroscopicity observed for a wide range of dry-generated dust. The upper and lower bounds of this set were used as sensitivity tests in order to determine the effect of the level of hygroscopicity of dust on CDNC. When $B_{F H H}=1.3$, the maximum contribution of insoluble particles to the predicted CDNC decreased to $15.1 \%$ as the mineral dust become less hygroscopic compared to the base case simulation (Table 3 ). Using the lower bound $B_{F H H}=1.1$, almost doubled the maximum contribution of dust on CDNC to $37.2 \%$ (Table 3 ). The set of the FHH parameters measured by Kumar et al. [2011a] represents the hygroscopicity of freshly emitted dust. Nevertheless, during the aging of mineral dust, its hygroscopicity increases as it is coated with soluble materials (e.g., sea salt or sulfates), and therefore the value of 1.1 should not considered as an upper limit of hygroscopicity, as a freshly emitted dust particle with diameter $100 \mathrm{~nm}$ and $B_{F H H}=$ 1.1 exhibits comparable hygroscopicity to a KT CCN with a $\left(\mathrm{NH}_{4}\right)_{2} \mathrm{SO}_{4}$ volume fraction of $10 \%$ [Kumar et al., 2011a]. Finally, the results are less sensitive to changes in $A_{F H H}$, as the contribution of insoluble particles on the predicted CDNC varies from $17.3 \%$ (when $A_{F H H}=1.5$ ) to $27.4 \%$ (when $A_{F H H}=3.0$ ) with the base case value being equal to $23.8 \%$ (when $A_{F H H}=2.25$; Table 3 ).

Table 3. Annual Mean Contribution of Mineral Dust to Cloud Droplet Number Concentrations Predicted by the Base Case and the Sensitivity Case Simulations

\begin{tabular}{lc}
\hline \multicolumn{1}{c}{ Simulation Scenario } & Contribution \\
\hline Base case & $23.8 \%$ \\
Sensitivity to size distribution & $18.0 \%$ \\
Sensitivity to $\mathrm{B}_{\mathrm{FHH}}\left(B_{F H H}=1.3\right)$ & $15.1 \%$ \\
Sensitivity to $\mathrm{B}_{\mathrm{FHH}}\left(B_{F H H}=1.1\right)$ & $37.2 \%$ \\
Sensitivity to $\mathrm{A}_{\mathrm{FHH}}\left(A_{F H H}=3.0\right)$ & $27.4 \%$ \\
Sensitivity to $\mathrm{A}_{\mathrm{FHH}}\left(A_{F H H}=1.5\right)$ & $17.3 \%$ \\
Sensitivity to anthropogenic & $88.9 \%$ \\
$\quad$ emissions & \\
\hline
\end{tabular}



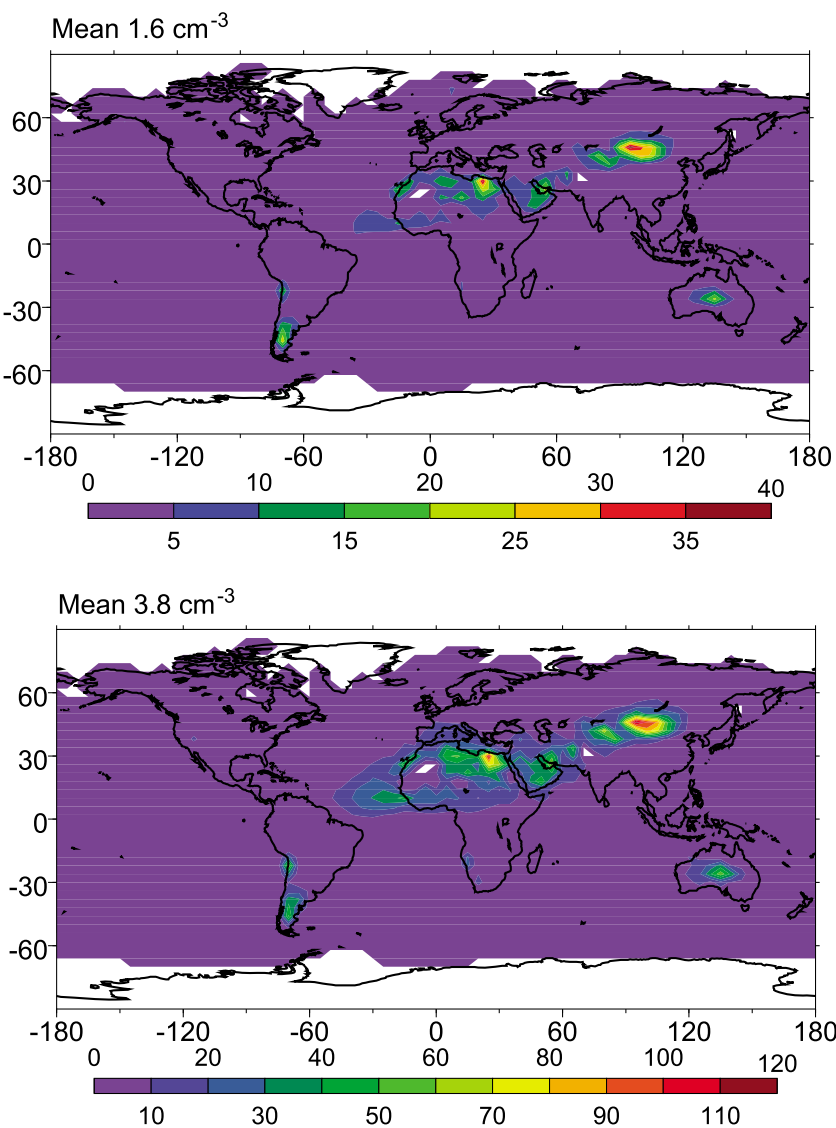

Figure 8. Predicted annual mean cloud droplet concentrations $\left(\mathrm{cm}^{-3}\right)$ activated from (top) completely insoluble dust particles and (bottom) aged dust particles for the lowest cloud-forming level (960 mbar).

\subsection{Sensitivity of Mineral Dust Contribution to CDNC to Anthropogenic Emissions}

[29] Current emission control policies are designed to lower the anthropogenic fine particulate matter concentration in order to meet the air quality standards. This will enhance the importance of mineral dust to total aerosol budget and cloud droplet formation over areas affected by anthropogenic emissions. To estimate an upper bound of mineral dust contribution to cloud droplet formation, a simulation excluding the anthropogenic emissions (emissions from fossil fuels) is conducted (pre-industrial conditions). In that case, the model predicted that close to deserts, up to $88.8 \%$ of cloud droplets formed from the activation of insoluble particles (Figure 8). On global average, the predicted contribution of mineral dust to $\mathrm{CDNC}$ is 12 times higher than the base case simulation $(3.7 \%$ instead of $0.3 \%$ in the base case).

\subsection{Sensitivity of Mineral Dust Contribution to CDNC to Atmospheric Aging}

[30] During atmospheric transport, fresh dust undergoes aging, which results in a coating of soluble material on its surface that augments its $\mathrm{CCN}$ activity. In order to address the first order effect of aging to dust $\mathrm{CCN}$ activity and CDNC, a sensitivity study is conducted where dust is assumed to be coated with $10 \%$ (in volume) ammonium sulfate (called hereafter "aged dust") and it follows the same size distribution as in the base case. The "unified dust activation framework" of Kumar et al. [2011a] (section 2.3) is used to calculate the CCN activity of aged dust; all other parameters are kept as in the "base case" simulation. Comparison between CDNC coming from the activation of completely insoluble dust (Figure 8a) and those from aged dust particles (Figure $8 \mathrm{~b}$ ) suggests that in the latter case the contribution of dust to CDNC increased by 2.5 times on average. The maximum CDNC (predicted over the Gobi Desert) increased from $38 \mathrm{~cm}^{-3}$ to $115 \mathrm{~cm}^{-3}$. In contrast with the completely insoluble dust particles (see section 3.3), the contribution of aged dust to $\mathrm{CCN}$ concentration increase with decreasing supersaturation. The increased hygroscopicity of aged dust together with its large dry diameter results in its activation at lower supersaturations than the smaller anthropogenic particles. At $0.4 \%$ supersaturation, the global annual mean contribution of mineral dust to total CCN concentration is $1 \%$ (with a maxima of $63 \%$ ) while at $0.2 \%$ supersaturation the global annual mean contribution increases to $1.3 \%$ (with a maxima of $75 \%$ ).

[31] Compared to freshly emitted dust, aged dust activates earlier in a cloudy updraft and grows to a larger wet size for a given supersaturation [Kumar et al., 2011b]; this can promote water uptake during the initial stages of cloud formation, eventually leading to supersaturation (and CDNC) depression. This is illustrated in Figure 9, which depicts the fractional change of CDNC between a simulation assuming no activation of dust and a simulation assuming activation of aged dust. The total CDNC is decreased by as much as $70 \%$ (Gobi Desert), 60\% over the Arabian Peninsula, 40\% over the Sahara Desert, 20\% over Australian desert, 5\% over the Southwestern United States, and increased by up to $20 \%$ over the Patagonian Desert. The CDNC also decreases over a wide range of areas such as Southern Europe (up to 5\%), Mediterranean Sea (up to 20\%), tropical Atlantic Ocean (up to $20 \%$ ), etc. As expected, $s_{\max }$ is also reduced significantly and the maximum decrease is observed over Arabian Peninsula and the Gobi Desert (up to $80 \%$ ). The $s_{\max }$ decreases by up to $40 \%$ over the Sahara Desert, $30 \%$ over

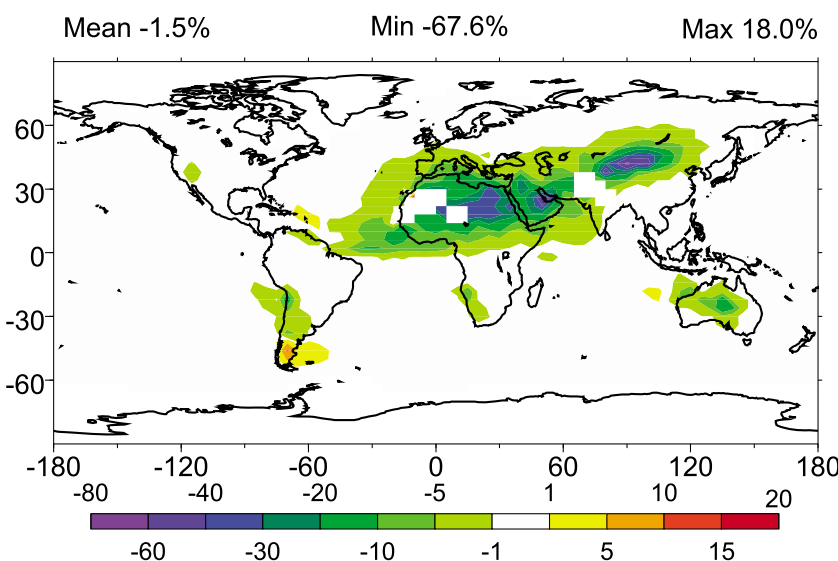

Figure 9. Predicted annual mean fractional change (\%) of cloud droplet number concentration for the lowest cloudforming level (960 mbar) between a simulation assuming no activation of mineral dust and a simulation assuming activation of aged dust. 
the Australian and Patagonian deserts, 5\% over the Southwestern United States and Southern Europe, 20\% over the Mediterranean Sea, and 30\% over the tropical Atlantic Ocean.

\section{Conclusions}

[32] This study is a first attempt to assess the contribution of freshly emitted insoluble dust particles to global CCN and cloud droplet number concentrations. Simulations are carried out with the NASA Global Modeling Initiative (GMI) Chemical Transport Model using wind fields computed with the Goddard Institute for Space Studies (GISS) general circulation model. GMI simulates global distributions of fossil fuel, biomass burning, marine, and dust aerosols; particles within each aerosol type are internally mixed and assumed to follow a prescribe size distribution. Particles with a significant amount of soluble material (the CCN activity of which is given by Köhler theory) are assumed to be sulfate, organic carbon, and sea salt. Dust is assumed insoluble, with the $\mathrm{CCN}$ activity given by adsorption activation theory; parameters required to constrain the theory are obtained from activation experiments of resuspended desert soil samples [Kumar et al., 2011b]. Calculation of droplet number from the aerosol simulation is done online in GMI, using the Kumar et al. [2009b] parameterization, which considers cloud droplet formation within an ascending air parcel containing an external mixture of soluble particles (that activate according to Köhler theory), and insoluble, wettable particles (that form droplets through adsorption activation). This new framework is used to assess the impact of dust and adsorption activation on the predicted droplet number concentration.

[33] The contribution of mineral dust to total particle and cloud droplet number concentration is relatively important in areas with high dust concentrations (e.g., deserts) with impacts that can extend across the tropical Atlantic Ocean. The predicted contribution of mineral dust to particle number concentrations is up to $40 \%$ over North African and Asian deserts and up to $15 \%$ over South American and Australian deserts. The effect of mineral dust on the annual average CDNC is up to $23.8 \%$ while the impact on the predicted CDNC across the tropical Atlantic Ocean is up to $10 \%$ close to the shore of the Western Sahara, up to $5 \%$ to the ocean, and less that $2 \%$ to the Caribbean Sea. Given that all the results in this study are expressed as annual averages, this contribution can be even more important during specific dust storm episodes. It is worth mentioning though that the model does not account for aerosol nucleation in the upper troposphere and thus underestimates the aerosol number concentration. This underestimation also affects the influence of dust on total aerosol number concentration and consequently on CDNC.

[34] Sensitivity tests show that the results are sensitive to the level of hygroscopicity of dust, and a $10 \%$ change in the $B_{F H H}$ parameter can lead to up to $40 \%$ change in the predicted number of activated insoluble particles. Moreover, the results are also sensitive to the size distribution of dust. Using a size distribution of dust, measured over Niger by Chou et al. [2008], which distributes dust in larger particles than the base case distribution (by d'Almeida [1987]), the predicted mineral dust particles decreased by $45 \%$ and the predicted cloud droplets activated from these insoluble particles by $20 \%$.

[35] As current emission control policies aim to reduce the concentration of anthropogenic aerosol, the impact of dust on global aerosol budget and cloud droplet formation will become larger in the future. The theoretical upper bound of the potential contribution of mineral dust to CDNC, based on a simulation that excludes anthropogenic emissions, is up to $88.8 \%$ over regions of high dust concentrations. Coating of dust by hygroscopic aerosol species during its aging enhances its CCN activity; a sensitivity study, assuming that dust is coated with $10 \%$ ammonium sulfate (in volume), results in an increase of cloud droplets activated from dust particles (by more than twofold). This enhanced hygroscopicity leads to significant water uptake in the early stages of cloud formation, resulting in a significant depletion of $S_{\max }$ (up to $80 \%$ over arid areas and up to $30 \%$ over their surrounding areas). This large depletion also results in a significant decrease of total CDNC (up to 70 and $40 \%$ over the Gobi and Sahara deserts, respectively) but also over their surrounding areas such as Southern Europe (up to 5\%), the Mediterranean Sea, and the tropical Atlantic Ocean (up to $20 \%$ ). These numbers represent the first order tendency of CDNC changes; assessment of the total response of the coupled system would require an interactive aerosol-cloudclimate model and is left for a future study. Despite the sensitivities and uncertainties seen here, this study shows that dust-cloud interactions can be important. Neglecting adsorption in predicting the dust $\mathrm{CCN}$ activity may introduce a significant bias in the models that treat dust-cloud interactions. Given that dust may affect precipitation in climate-sensitive areas, the ability to capture the complex impact of mineral dust on cloud droplet formation is an important issue for global and regional models. This study demonstrates that a comprehensive treatment of the inherent hydrophilicity from adsorption and acquired hygroscopicity from soluble salts in dust particles is straightforward and well within the capabilities of current model frameworks.

[36] Acknowledgments. We would like to acknowledge support from NASA-ACMAP, ConocoPhillips, and NOAA. We are also thankful for the important comments by three anonymous reviewers, which have helped to improve the quality of the manuscript.

\section{References}

Anderson, B. E., W. B. Grant, G. L. Gregory, E. V. Browell, J. E. Collins, G. W. Sachse, D. R. Bagwell, C. H. Hudgins, B. R. Blake, and N. J. Blake (1996), Aerosols from biomass burning over the tropical South Atlantic region: Distributions and impacts, J. Geophys. Res., 101(D19), 24,117-24,137, doi:10.1029/96JD00717.

Barahona, D., and A. Nenes (2007), Parameterization of cloud droplet formation in large-scale models: Including effects of entrainment, J. Geophys. Res., 112, D16206, doi:10.1029/2007JD008473.

Barahona, D., J. Rodriguez, and A. Nenes (2010a), Sensitivity of the global distribution of cirrus ice crystal concentration to heterogeneous freezing, J. Geophys. Res., 115, D23213, doi:10.1029/2010JD014273.

Barahona, D., R. E. L. West, P. Stier, S. Romakkaniemi, H. Kokkola, and A. Nenes (2010b), Comprehensively accounting for the effect of giant CCN in cloud activation parameterizations, Atmos. Chem. Phys., 10(5), 2467-2473, doi:10.5194/acp-10-2467-2010.

Barahona, D., R. E. P. Sotiropoulou, and A. Nenes (2011), Global distribution of cloud droplet number concentration, autoconversion rate and aerosol indirect effect under diabatic droplet activation, J. Geophys. Res., 116, D09203, doi:10.1029/2010JD015274. 
Bennartz, R. (2007), Global assessment of marine boundary layer cloud droplet number concentration from satellite, J. Geophys. Res., 112, D02201, doi:10.1029/2006JD007547.

Bower, K. N., et al. (1997), Observations and modelling of the processing of aerosol by a hill cap cloud, Atmos. Environ., 31(16), 2527-2543, doi:10.1016/S1352-2310(96)00317-2.

Bower, K. N., et al. (1999), The Great Dun Fell Experiment 1995: An overview, Atmos. Res., 50(3-4), 151-184, doi:10.1016/S0169-8095(98) 00103-3.

Brenguier, J. L., H. Pawlowska, and L. Schuller (2003), Cloud microphysical and radiative properties for parameterization and satellite monitoring of the indirect effect of aerosol on climate, J. Geophys. Res., 108(D15), 8632, doi:10.1029/2002JD002682.

Burnet, F., and J. L. Brenguier (2007), Observational study of the entrainment-mixing process in warm convective clouds, J. Atmos. Sci., 64(6), 1995-2011, doi:10.1175/JAS3928.1

Chen, W. T., A. Nenes, H. Liao, P. J. Adams, J. L. F. Li, and J. H. Seinfeld (2010), Global climate response to anthropogenic aerosol indirect effects: Present day and year 2100, J. Geophys. Res., 115, D12207, doi:10.1029/ 2008JD011619.

Chiapello, I., C. Moulin, and J. M. Prospero (2005), Understanding the long-term variability of African dust transport across the Atlantic as recorded in both Barbados surface concentrations and large-scale Total Ozone Mapping Spectrometer (TOMS) optical thickness, J. Geophys. Res., 110, D18S10, doi:10.1029/2004JD005132.

Chou, C., P. Formenti, M. Maille, P. Ausset, G. Helas, M. Harrison, and S. Osborne (2008), Size distribution, shape, and composition of mineral dust aerosols collected during the African Monsoon Multidisciplinary Analysis Special Observation Period 0: Dust and Biomass-Burning Experiment field campaign in Niger, January 2006, J. Geophys. Res., 113, D00C10, doi:10.1029/2008JD009897.

Chuang, C. C., J. E. Penner, K. E. Taylor, A. S. Grossman, and J. J. Walton (1997), An assessment of the radiative effects of anthropogenic sulfate, J. Geophys. Res., 102(D3), 3761-3778, doi:10.1029/96JD03087.

Chuang, P. Y., D. R. Collins, H. Pawlowska, J. R. Snider, H. H. Jonsson, J. L. Brenguier, R. C. Flagan, and J. H. Seinfeld (2000), CCN measurements during ACE-2 and their relationship to cloud microphysical properties, Tellus, Ser. B, 52(2), 843-867, doi:10.1034/j.1600-0889.2000.00018.x.

Considine, D. B., D. J. Bergmann, and H. Liu (2005), Sensitivity of Global Modeling Initiative chemistry and transport model simulations of radon-222 and lead-210 to input meteorological data, Atmos. Chem. Phys., 5, 3389-3406, doi:10.5194/acp-5-3389-2005

Coz, E., F. J. Gomez-Moreno, M. Pujadas, G. S. Casuccio, T. L. Lersch and B. Artinano (2009), Individual particle characteristics of North African dust under different long-range transport scenarios, Atmos Environ., 43(11), 1850-1863, doi:10.1016/j.atmosenv.2008.12.045.

d'Almeida, G. A. (1987), On the variability of desert aerosol radiative characteristics, J. Geophys. Res., 92(D3), 3017-3026, doi:10.1029/ JD092iD03p03017.

DeMott, P. J., K. Sassen, M. R. Poellot, D. Baumgardner, D. C. Rogers, S. D. Brooks, A. J. Prenni, and S. M. Kreidenweis (2003), African dust aerosols as atmospheric ice nuclei, Geophys. Res. Lett., 30(14), 1732 doi:10.1029/2003GL017410.

Di Giuseppe, F. (2005), Sensitivity of one-dimensional radiative biases to vertical cloud-structure assumptions: Validation with aircraft data, $Q . J . R$ Meteorol. Soc., 131(608), 1655-1676, doi:10.1256/qj.03.129.

Dong, X. Q., and G. G. Mace (2003), Arctic stratus cloud properties and radiative forcing derived from ground-based data collected at Barrow, Alaska, J. Clim., 16(3), 445-461, doi:10.1175/1520-0442(2003)016<0445 ASCPAR $>2.0 . \mathrm{CO} \cdot 2$

Dong, X. Q., T. P. Ackerman, E. E. Clothiaux, P. Pilewskie, and Y. Han (1997), Microphysical and radiative properties of boundary layer stratiform clouds deduced from ground-based measurements, J. Geophys. Res., 102(D20), 23,829-23,843, doi:10.1029/97JD02119.

Dong, X. Q., T. P. Ackerman, and E. E. Clothiaux (1998), Parameterizations of the microphysical and shortwave radiative properties of boundary layer stratus from ground-based measurements, J. Geophys. Res., 103 (D24), 31,681-31,693, doi:10.1029/1998JD200047.

Dong, X. Q., P. Minnis, T. P. Ackerman, E. E. Clothiaux, G. G. Mace, C. N. Long, and J. C. Liljegren (2000), A 25-month database of stratus cloud properties generated from ground-based measurements at the Atmospheric Radiation Measurement Southern Great Plains Site, J. Geophys. Res., 105(D4), 4529-4537, doi:10.1029/1999JD901159.

Dong, X. Q., P. Minnis, and B. K. Xi (2005), A climatology of midlatitude continental clouds from the ARM SGP Central Facility: Part I: Low-level cloud macrophysical, microphysical, and radiative properties, J. Clim., 18(9), 1391-1410, doi:10.1175/JCLI3342.1.
Ekman, A. M. L. (2002), Small-scale patterns of sulfate aerosol climate forcing simulated with a high-resolution regional climate model, Tellus, Ser. B, 54(2), 143-162, doi:10.1034/j.1600-0889.2002.00282.x.

Feingold, G., W. R. Cotton, S. M. Kreidenweis, and J. T. Davis (1999), The impact of giant cloud condensation nuclei on drizzle formation in stratocumulus: Implications for cloud radiative properties, J. Atmos. Sci. 56(24), 4100-4117, doi:10.1175/1520-0469(1999)056<4100:TIOGCC $>2.0$. $\mathrm{CO} ; 2$

Field, P. R., O. Mohler, P. Connolly, M. Kramer, R. Cotton, A. J. Heymsfield, H. Saathoff, and M. Schnaiter (2006), Some ice nucleation characteristics of Asian and Saharan desert dust, Atmos. Chem. Phys., 6, 2991-3006, doi:10.5194/acp-6-2991-2006.

Fountoukis, C., and A. Nenes (2005), Continued development of a cloud droplet formation parameterization for global climate models, J. Geophys. Res., 110, D11212, doi:10.1029/2004JD005591.

Fountoukis, C., et al. (2007), Aerosol-cloud drop concentration closure for clouds sampled during the International Consortium for Atmospheric Research on Transport and Transformation 2004 campaign, J. Geophys. Res., 112, D10S30, doi:10.1029/2006JD007272.

Gibson, E. R., K. M. Gierlus, P. K. Hudson, and V. H. Grassian (2007), Generation of internally mixed insoluble and soluble aerosol particles to investigate the impact of atmospheric aging and heterogeneous processing on the CCN activity of mineral dust aerosol, Aerosp. Sci. Technol., 41(10), 914-924, doi:10.1080/02786820701557222.

Ginoux, P., M. Chin, I. Tegen, J. M. Prospero, B. Holben, O. Dubovik, and S.-J. Lin (2001), Sources and distributions of dust aerosols simulated with the GOCART model, J. Geophys. Res., 106, 20,255-20,273, doi:10.1029/ 2000JD000053.

Grini, A., G. Myhre, C. S. Zender, and I. S. A. Isaksen (2005), Model simulations of dust sources and transport in the global atmosphere: Effects of soil erodibility and wind speed variability, J. Geophys. Res. 110, D02205, doi:10.1029/2004JD005037.

Guibert, S., J. R. Snider, and J. L. Brenguier (2003), Aerosol activation in marine stratocumulus clouds: 1. Measurement validation for a closure study, J. Geophys. Res., 108(D15), 8628, doi:10.1029/2002JD002678.

Gultepe, I., and G. A. Isaac (2002), Effects of air mass origin on Arctic cloud microphysical parameters for April 1998 during FIRE.ACE, J. Geophys. Res., 107(C10), 8029, doi:10.1029/2000JC000440.

Gultepe, I., G. A. Isaac, and K. B. Strawbridge (2001), Variability of cloud microphysical and optical parameters obtained from aircraft and satellite remote sensing measurements during RACE, Int. J. Climatol., 21(4), 507-525, doi:10.1002/joc.582.

Gultepe, I., G. A. Isaac, J. Key, J. Intrieri, D. O. Starr, and K. B. Strawbridge (2004), Dynamical and microphysical characteristics of Arctic clouds using integrated observations collected over SHEBA during the April 1998 FIRE.ACE flights of the Canadian Convair, Meteorol. Atmos. Phys. 85(4), 235-263, doi:10.1007/s00703-003-0009-z.

Harshvardhan, S. E. Schwartz, C. M. Benkovitz, and G. Guo (2002), Aerosol influence on cloud microphysics examined by satellite measurements and chemical transport modeling, J. Atmos. Sci., 59(3), 714-725, doi:10.1175/ 1520-0469(2002)059<0714:AIOCME $>2.0 . \mathrm{CO} ; 2$

Henning, S., E. Weingartner, S. Schmidt, M. Wendisch, H. W. Gaggeler, and U. Baltensperger (2002), Size-dependent aerosol activation at the high-alpine site Jungfraujoch (3580 m asl), Tellus, Ser. B, 54(1), 82-95, doi:10.1034/j.1600-0889.2002.00299.x.

Henrich, F., H. Siebert, E. Jakel, R. A. Shaw, and M. Wendisch (2010), Collocated measurements of boundary layer cloud microphysical and radiative properties: A feasibility study, J. Geophys. Res., 115, D24214, doi:10.1029/2010JD013930.

Herich, H., T. Tritscher, A. Wiacek, M. Gysel, E. Weingartner, U. Lohmann, U. Baltensperger, and D. J. Cziczo (2009), Water uptake of clay and desert dust aerosol particles at sub- and supersaturated water vapor conditions, Phys. Chem. Chem. Phys., 11(36), 7804-7809, doi:10.1039/b901585j.

Herman, G. F., and J. A. Curry (1984), Observational and theoretical studies of solar radiation in arctic stratus clouds, J. Clim. Appl. Meteorol., 23(1), 5-24, doi:10.1175/1520-0450(1984)023<0005:OATSOS $>2.0 . \mathrm{CO} ; 2$

Hobbs, P. V., and A. L. Rangno (1998), Microstructures of low and middlelevel clouds over the Beaufort Sea, Q. J. R. Meteorol. Soc., 124(550), 2035-2071, doi:10.1002/qj.49712455012.

Hoose, C., U. Lohmann, R. Erdin, and I. Tegen (2008a), The global influence of dust mineralogical composition on heterogeneous ice nucleation in mixed-phase clouds, Environ. Res. Lett., 3(2), 025003, doi:10.1088/ 1748-9326/3/2/025003

Hoose, C., U. Lohmann, R. Bennartz, B. Croft, and G. Lesins (2008b), Global simulations of aerosol processing in clouds, Atmos. Chem. Phys., 8(23), 6939-6963, doi:10.5194/acp-8-6939-2008.

Hoppel, W. A., G. M. Frick, J. Fitzgerald, and R. E. Larson (1994), Marine boundary-layer measurements of new particle formation and the effects 
nonprecipitating clouds have on aerosol-size distribution, J. Geophys. Res., 99(D7), 14,443-14,459, doi:10.1029/94JD00797.

Iacobellis, S. F., and R. C. J. Somerville (2006), Evaluating parameterizations of the autoconversion process using a single-column model and Atmospheric Radiation Measurement Program measurements, J. Geophys. Res., 111, D02203, doi:10.1029/2005JD006296.

Jeong, G. R., and I. N. Sokolik (2007), Effect of mineral dust aerosols on the photolysis rates in the clean and polluted marine environments, J. Geophys. Res., 112, D21308, doi:10.1029/2007JD008442.

Kallos, G., A. Papadopoulos, P. Katsafados, and S. Nickovic (2006), Transatlantic Saharan dust transport: Model simulation and results, J. Geophys. Res., 111, D09204, doi:10.1029/2005JD006207.

Kallos, G., M. Astitha, P. Katsafados, and C. Spyrou (2007), Long-range transport of anthropogenically and naturally produced particulate matter in the Mediterranean and North Atlantic: Current state of knowledge, J. Appl. Meteorol. Climatol., 46(8), 1230-1251, doi:10.1175/JAM2530.1.

Karyampudi, V. M., and T. N. Carlson (1988), Analysis and numerica simulations of the Saharan air layer and its effect on easterly wave disturbances, J. Atmos. Sci., 45(21), 3102-3136, doi:10.1175/1520-0469(1988) $045<3102$ :AANSOT $>2.0 . \mathrm{CO} ; 2$.

Karyampudi, V. M., et al. (1999), Validation of the Saharan dust plume conceptual model using Lidar, Meteosat, and ECMWF data, Bull. Am. Meteorol. Soc., 80(6), 1045-1075, doi:10.1175/1520-0477(1999)080< 1045:VOTSDP $>2.0 . \mathrm{CO} ; 2$

Kelly, J. T., C. C. Chuang, and A. S. Wexler (2007), Influence of dust composition on cloud droplet formation, Atmos. Environ., 41(14) 2904-2916, doi:10.1016/j.atmosenv.2006.12.008.

Koch, D., and D. Rind (1998), Beryllium 10/beryllium 7 as a tracer of stratospheric transport, J. Geophys. Res., 103(D4), 3907-3917, doi:10.1029/ 97JD03117.

Koehler, K. A., S. M. Kreidenweis, P. J. DeMott, M. D. Petters, A. J. Prenni, and C. M. Carrico (2009), Hygroscopicity and cloud droplet activation of mineral dust aerosol, Geophys. Res. Lett., 36, L08805, doi:10.1029/2009GL037348.

Komppula, M., H. Lihavainen, V. M. Kerminen, M. Kulmala, and Y. Viisanen (2005), Measurements of cloud droplet activation of aerosol particles at a clean subarctic background site, J. Geophys. Res., 110, D06204, doi:10.1029/2004JD005200.

Kumar, P., A. Nenes, and I. N. Sokolik (2009a), Importance of adsorption for CCN activity and hygroscopic properties of mineral dust aerosol, Geophys. Res. Lett., 36, L24804, doi:10.1029/2009GL040827.

Kumar, P., I. N. Sokolik, and A. Nenes (2009b), Parameterization of cloud droplet formation for global and regional models: Including adsorption activation from insoluble CCN, Atmos. Chem. Phys., 9(7), 2517-2532, doi:10.5194/acp-9-2517-2009.

Kumar, P., I. N. Sokolik, and A. Nenes (2011a), Measurements of cloud condensation nuclei activity and droplet activation kinetics of wet processed regional dust samples and minerals, Atmos. Chem. Phys., 11(16), 8661-8676, doi:10.5194/acp-11-8661-2011.

Kumar, P., I. N. Sokolik, and A. Nenes (2011b), Cloud condensation nuclei activity and droplet activation kinetics of fresh unprocessed regiona dust samples and minerals, Atmos. Chem. Phys., 11(7), 3527-3541, doi:10.5194/acp-11-3527-2011.

Lafon, S., I. N. Sokolik, J. L. Rajot, S. Caquineau, and A. Gaudichet (2006) Characterization of iron oxides in mineral dust aerosols: Implications for light absorption, J. Geophys. Res., 111, D21207, doi:10.1029/ 2005JD007016.

Lance, S., A. Nenes, and T. A. Rissman (2004), Chemical and dynamica effects on cloud droplet number: Implications for estimates of the aerosol indirect effect, J. Geophys. Res., 109, D22208, doi:10.1029/ 2004JD004596.

Lathem, T. L., P. Kumar, A. Nenes, J. Dufek, I. N. Sokolik, M. Trail, and A. Russell (2011), Hygroscopic properties of volcanic ash, Geophys. Res. Lett., 38, L11802, doi:10.1029/2011GL047298.

Leaitch, W. R., G. A. Isaac, J. W. Strapp, C. M. Banic, and H. A. Wiebe (1992), The relationship between cloud droplet number concentrations and anthropogenic pollution - observations and climatic implications, J. Geophys. Res., 97(D2), 2463-2474

Lee, Y. H., K. Chen, and P. J. Adams (2009), Development of a global model of mineral dust aerosol microphysics, Atmos. Chem. Phys., 9(7), 2441-2458, doi:10.5194/acp-9-2441-2009.

Lehmann, K., H. Siebert, and R. A. Shaw (2009), Homogeneous and inhomogeneous mixing in cumulus clouds: Dependence on local turbulence structure, J. Atmos. Sci., 66(12), 3641-3659, doi:10.1175/2009JAS3012.1.

Leibensperger, E. M., W. T. Chen, J. H. Seinfeld, A. Nenes, P. J. Adams, D. G. Streets, N. Kumar, and D. Rind (2011), Climatic effects of 1950 2050 changes in US anthropogenic aerosols - Part 1: Aerosol trends and radiative forcing, Atmos. Chem. Phys. Discuss., 11, 24,085-24,125, doi:10.5194/acpd-11-24085-2011.
Levin, Z., and W. R. Cotton (Eds.) (2009), Aerosol Pollution Impact on Precipitation: A Scientific Review, 386 pp., Springer, Dordrecht, Netherlands.

Levin, Z., A. Teller, E. Ganor, and Y. Yin (2005), On the interactions of mineral dust, sea-salt particles, and clouds: A measurement and modeling study from the Mediterranean Israeli Dust Experiment campaign, J Geophys. Res., 110, D20202, doi:10.1029/2005JD005810.

Lihavainen, H., et al. (2008), Measurements of the relation between aerosol properties and microphysics and chemistry of low level liquid water clouds in Northern Finland, Atmos. Chem. Phys., 8(23), 6925-6938, doi:10.5194/acp-8-6925-2008

Liu, G. S., H. F. Shao, J. A. Coakley, J. A. Curry, J. A. Haggerty, and M. A. Tschudi (2003), Retrieval of cloud droplet size from visible and microwave radiometric measurements during INDOEX: Implication to aerosols' indirect radiative effect, J. Geophys. Res., 108(D1), 4006, doi:10.1029/2001JD001395.

Liu, X. H., J. E. Penner, and M. Herzog (2005), Global modeling of aerosol dynamics: Model description, evaluation, and interactions between sulfate and nonsulfate aerosols, J. Geophys. Res., 110, D18206, doi:10.1029/ 2004JD005674

Luo, Y. L., K. M. Xu, H. Morrison, G. M. McFarquhar, Z. Wang, and G. Zhang (2008), Multi-layer arctic mixed-phase clouds simulated by a cloud-resolving model: Comparison with ARM observations and sensitivity experiments, J. Geophys. Res., 113, D12208, doi:10.1029/2007JD009563.

Ma, J. Z., Y. Chen, W. Wang, P. Yan, H. J. Liu, S. Y. Yang, Z. J. Hu, and J. Lelieveld (2010), Strong air pollution causes widespread hazeclouds over China, J. Geophys. Res., 115, D18204, doi:10.1029/ 2009JD013065.

Manktelow, P. T., K. S. Carslaw, G. W. Mann, and D. V. Spracklen (2010), The impact of dust on sulfate aerosol, $\mathrm{CN}$ and $\mathrm{CCN}$ during an East Asian dust storm, Atmos. Chem. Phys., 10(2), 365-382, doi:10.5194/acp-10365-2010

Menon, S., V. K. Saxena, P. Durkee, B. N. Wenny, and K. Nielsen (2002), Role of sulfate aerosols in modifying the cloud albedo: A closure experiment, Atmos. Res., 61(3), 169-187, doi:10.1016/S0169-8095(01) 00140-5.

Merikanto, J., D. V. Spracklen, K. J. Pringle, and K. S. Carslaw (2010), Effects of boundary layer particle formation on cloud droplet number and changes in cloud albedo from 1850 to 2000, Atmos. Chem. Phys., 10(2), 695-705, doi:10.5194/acp-10-695-2010.

Meskhidze, N., W. L. Chameides, A. Nenes, and G. Chen (2003), Iron mobilization in mineral dust: Can anthropogenic $\mathrm{SO}_{2}$ emissions affect ocean productivity?, Geophys. Res. Lett., 30(21), 2085, doi:10.1029/ 2003GL018035.

Meskhidze, N., W. L. Chameides, and A. Nenes (2005a), Dust and pollution: A recipe for enhanced ocean fertilization?, J. Geophys. Res., 110, D03301, doi:10.1029/2004JD005082.

Meskhidze, N., A. Nenes, W. C. Conant, and J. H. Seinfeld (2005b), Evaluation of a new cloud droplet activation parameterization with in situ data from CRYSTAL-FACE and CSTRIPE, J. Geophys. Res., 110, D16202, doi:10.1029/2004JD005703.

Minnis, P. P. W. Heck, D. F. Young, C. W. Fairall, and J. B. Snider (1992), Stratocumulus cloud properties derived from simultaneous satellite and island-based instrumentation during fire, J. Appl. Meteorol., 31(4), 317-339, doi:10.1175/1520-0450(1992)031<0317:SCPDFS>2.0.CO;2.

Mitsakou, C., G. Kallos, N. Papantoniou, C. Spyrou, S. Solomos, M. Astitha, and C. Housiadas (2008), Saharan dust levels in Greece and received inhalation doses, Atmos. Chem. Phys., 8(23), 7181-7192, doi:10.5194/acp-8-7181-2008.

Morales, R., and A. Nenes (2010), Characteristic updrafts for computing distribution-averaged cloud droplet number and stratocumulus cloud properties, J. Geophys. Res., 115, D18220, doi:10.1029/2009JD013233. Nenes, A., and J. H. Seinfeld (2003), Parameterization of cloud droplet formation in global climate models, J. Geophys. Res., 108(D14), 4415, doi:10.1029/2002JD002911.

Nenes, A., S. Ghan, H. Abdul-Razzak, P. Y. Chuang, and J. H. Seinfeld (2001), Kinetic limitations on cloud droplet formation and impact on cloud albedo, Tellus, Ser. B, 53(2), 133-149, doi:10.1034/j.1600-0889. 2001.d01-12.x.

Penner, J. E., J. Quaas, T. Storelvmo, T. Takemura, O. Boucher, H. Guo, A. Kirkevag, J. E. Kristjansson, and O. Seland (2006), Model intercomparison of indirect aerosol effects, Atmos. Chem. Phys., 6, 3391-3405, doi:10.5194/acp-6-3391-2006.

Portin, H. J., M. Komppula, A. P. Leskinen, S. Romakkaniemi, A. Laaksonen, and K. E. J. Lehtinen (2009), Observations of aerosol-cloud interactions at the Puijo semi-urban measurement station, Boreal Environ. Res., 14(4), 641-653.

Pringle, K. J., H. Tost, A. Pozzer, U. Poschl, and J. Lelieveld (2010a), Global distribution of the effective aerosol hygroscopicity parameter for 
CCN activation, Atmos. Chem. Phys., 10(12), 5241-5255, doi:10.5194/ acp-10-5241-2010.

Pringle, K. J., H. Tost, S. Message, B. Steil, D. Giannadaki, A. Nenes, C. Fountoukis, P. Stier, E. Vignati, and J. Leieved (2010b), Description and evaluation of GMXe: A new aerosol submodel for global simulations (v1), Geosci. Model Develop., 3(2), 391-412, doi:10.5194/gmd-3-3912010.

Prospero, J. M., R. J. Charlson, V. Mohnen, R. Jaenicke, A. C. Delany, J. Moyers, W. Zoller, and K. Rahn (1983), The atmospheric aerosol system: An overview, Rev. Geophys., 21(7), 1607-1629, doi:10.1029/ RG021i007p01607.

Prospero, J. M., I. Olmez, and M. Ames (2001), Al and Fe in PM 2.5 and PM 10 suspended particles in south-central Florida: The impact of the long range transport of African mineral dust, Water Air Soil Pollut. 125(1), 291-317, doi:10.1023/A:1005277214288.

Querol, X., et al. (2009), African dust contributions to mean ambient PM10 mass-levels across the Mediterranean Basin, Atmos. Environ., 43(28), 4266-4277, doi:10.1016/j.atmosenv.2009.06.013.

Radke, L. F., D. A. Hegg, J. H. Lyons, C. A. Brock, P. V. Hobbs, R. Weiss, and R. Rasmussen (1988), Airborne measurements on smokes from biomass burning, in Aerosols and Climate, edited by P. V. Hobbs and M. P. McCormick, pp. 411-422, A. Deepak, Hampton, Va.

Rausch, J., A. Heidinger, and R. Bennartz (2010), Regional assessment of microphysical properties of marine boundary layer cloud using the PATMOS-x data set, J. Geophys. Res., 115, D23212, doi:10.1029/ 2010JD014468.

Rind, D., and J. Lerner (1996), Use of on-line tracers as a diagnostic tool in general circulation model development. 1. Horizontal and vertical transport in the troposphere, J. Geophys. Res., 101(D7), 12,667-12,683, doi:10.1029/96JD00551.

Romakkaniemi, S., G. McFiggans, K. N. Bower, P. Brown, H. Coe, and T. W. Choularton (2009), A comparison between trajectory ensemble and adiabatic parcel modeled cloud properties and evaluation against airborne measurements, J. Geophys. Res., 114, D06214, doi:10.1029/ 2008JD011286.

Rotman, D. A., et al. (2001), Global Modeling Initiative assessment model: Model description, integration, and testing of the transport shell, J. Geophys. Res., 106(D2), 1669-1691, doi:10.1029/2000JD900463.

Sassen, K., Z. Wang, V. I. Khvorostyanov, G. L. Stephens, and A. Bennedetti (2002), Cirrus cloud ice water content radar algorithm evaluation using an explicit cloud microphysical model, J. Appl. Meteorol., 41(6), 620-628, doi:10.1175/1520-0450(2002)041<0620:CCIWCR >2.0 $\mathrm{CO} ; 2$.

Saxena, V. K., P. A. Durkee, S. Menon, J. Anderson, K. L. Burns, and K. E. Nielsen (1996), Physico-chemical measurements to investigate regional cloud climate feedback mechanisms, Atmos. Environ., 30(10-11), 1573-1579, doi:10.1016/1352-2310(95)00453-X.

Schüller, L., R. Bennartz, J. Fischer, and J. L. Brenguier (2005), An algorithm for the retrieval of droplet number concentration and geometrical thickness of stratiform marine boundary layer clouds applied to MODIS radiometric observations, J. Appl. Meteorol., 44(1), 28-38, doi:10.1175/ JAM-2185.1.

Seisel, S., C. Borensen, R. Vogt, and R. Zellner (2005), Kinetics and mechanism of the uptake of $\mathrm{N} 2 \mathrm{O} 5$ on mineral dust at $298 \mathrm{~K}$, Atmos. Chem Phys., 5, 3423-3432, doi:10.5194/acp-5-3423-2005.

Sokolik, I. N., D. M. Winker, G. Bergametti, D. A. Gillette, G. Carmichael, Y. J. Kaufman, L. Gomes, L. Schuetz, and J. E. Penner (2001), Introduction to special section: Outstanding problems in quantifying the radiative impacts of mineral dust, J. Geophys. Res., 106(D16), 18,015-18,027, doi:10.1029/2000JD900498

Solomos, S., G. Kallos, J. Kushta, M. Astitha, C. Tremback, A. Nenes, and Z. Levin (2011), An integrated modeling study on the effects of mineral dust and sea salt particles on clouds and precipitation, Atmos. Chem. Phys., 11(2), 873-892, doi:10.5194/acp-11-873-2011.

Sorjamaa, R., and A. Laaksonen (2007), The effect of $\mathrm{H}_{2} \mathrm{O}$ adsorption on cloud drop activation of insoluble particles: A theoretical framework, Atmos. Chem. Phys., 7(24), 6175-6180, doi:10.5194/acp-7-6175-2007.

Straub, D. J., T. Lee, and J. L. Collett (2007), Chemical composition of marine stratocumulus clouds over the eastern Pacific Ocean, J. Geophys. Res., 112, D04307, doi:10.1029/2006JD007439.

Teller, A and Z Levin (2006), The effects of aerosols on precipitation and dimensions of subtropical clouds: A sensitivity study using a numerical cloud model, Atmos. Chem. Phys., 6, 67-80, doi:10.5194/acp-6-67-2006.

Twohy, C. H., et al. (2009), Saharan dust particles nucleate droplets in eastern Atlantic clouds, Geophys. Res. Lett., 36, L01807, doi:10.1029/ 2008GL035846.

vanZanten, M. C., B. Stevens, G. Vali, and D. H. Lenschow (2005), Observations of drizzle in nocturnal marine stratocumulus, J. Atmos. Sci., 62(1), 88-106, doi:10.1175/JAS-3355.1.

Wilcox, E. M., G. Roberts, and V. Ramanathan (2006), Influence of aerosols on the shortwave cloud radiative forcing from North Pacific oceanic clouds: Results from the Cloud Indirect Forcing Experiment (CIFEX), Geophys. Res. Lett., 33, L21804, doi:10.1029/2006GL027150.

Yin, Y., and L. Chen (2007), The effects of heating by transported dust layers on cloud and precipitation: A numerical study, Atmos. Chem. Phys., 7, 3497-3505, doi:10.5194/acp-7-3497-2007.

Zender, C. S., and E. Y. Kwon (2005), Regional contrasts in dust emission responses to climate, J. Geophys. Res., 110, D13201, doi:10.1029/ 2004JD005501.

Zhao, C. S., et al. (2006), Aircraft measurements of cloud droplet spectral dispersion and implications for indirect aerosol radiative forcing, Geophys. Res. Lett., 33, L16809, doi:10.1029/2006GL026653.

D. Barahona, NASA Goddard Space Flight Center, 8800 Greenbelt Rd., Greenbelt, MD 20771, USA.

V. A. Karydis, A. Nenes, and I. N. Sokolik, School of Earth and Atmospheric Sciences, Georgia Institute of Technology, 311 Ferst Dr., Atlanta, GA 30332, USA. (athanasios.nenes@gatech.edu)

P. Kumar, SABIC Innovative Plastics, 1 Noryl Ave., Selkirk, NY 12158 9765 , USA. 